\title{
العلموية وأخلاقيات البيولوجيا
}

\section{Scientism and Bioethics}

ملخص: تسعى الدراسة إلى تحديد الأخلاق المطلوبة اليوم بغية تسييج الأبحاث البيولوجية

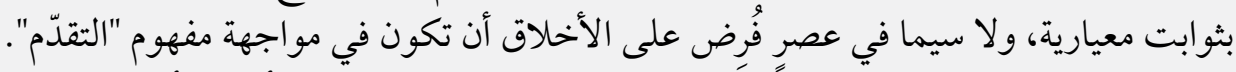

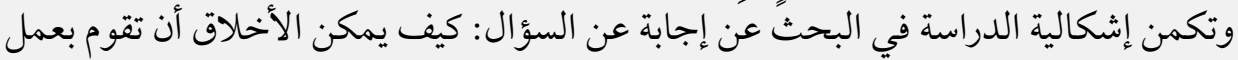

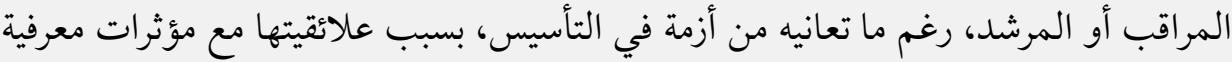

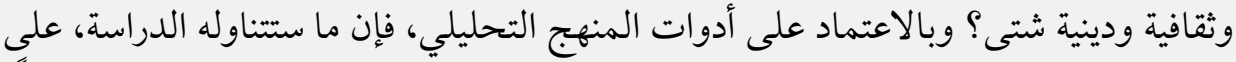

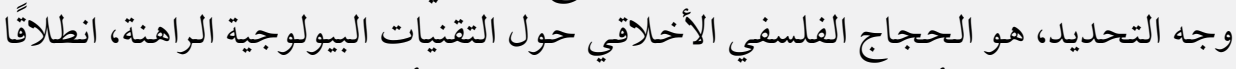

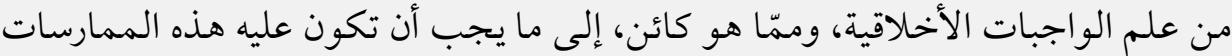
البيولوجية، في سياق فلسفي يروم إثبات خطر "العلموية"، ومشروعية التخوف البيولوجي،

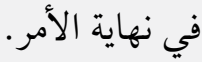
كلمات مفتاحية: ديونطولوجيا، الجينوم، المسؤولية، قدسيّة الحياة، العلموية، التطور، القلق البيولوجي.

Abstract: This study seeks to define the ethics required today in order to constrain evolutionary biological thought with normative constants, especially in an era where ethics is forced to oppose the concept of progress. The objective of this study is to search for an answer to the question: How can ethics perform the work of an observer and guide, despite suffering from a foundational crisis due to its relationship with various cultural and religious influences? Relying on the analytical method, this study will specifically address the ethical philosophical arguments about current biological techniques, starting from the notion of moral obligation together with what it entails for biological practice. The philosophical goal is to prove the danger of Scientism, and the legitimacy of concern about biological research.

Keywords: Deontology, Genome, Responsibility, Sanctity of Life, Scientism, Evolution.

* محاضر غير متفرغ في الجامعة الأردنية، حاصل على الدكتوراه في الفلسفة، باحث في فلسفة الأخلاق. Holder of Ph.D in Philosophy, Reseacher in the Philosophy of Ethics, and Part-time Lecturer at the University of Jordan. 


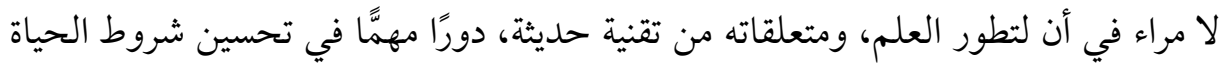

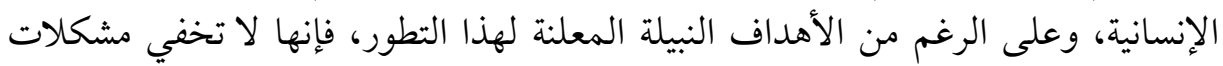

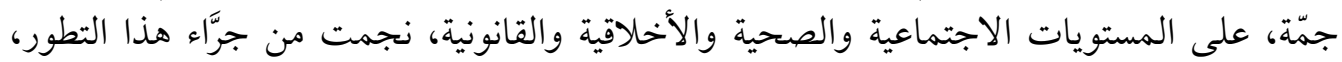

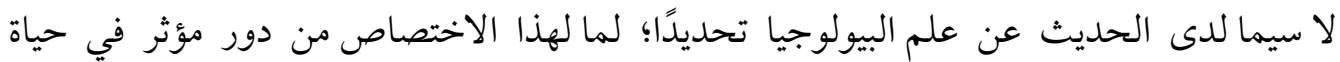
الكائنات الحية، وعلى رأسها الإنسان نفسه.

أدى تطور النقاشات الأخلاقية والقانونية في مجال البيولوجيا، إلى تبنّي منظمة الأمم المتحدة للتربية

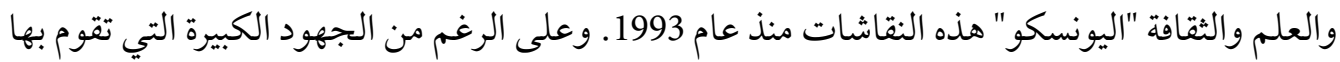

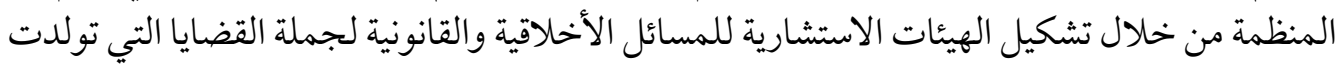

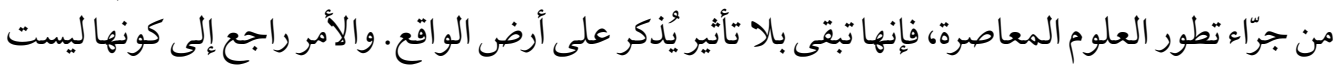

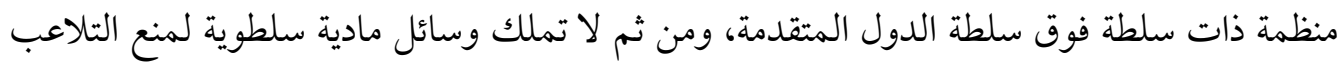

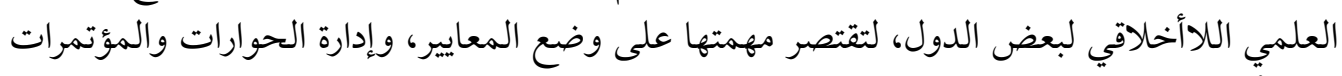

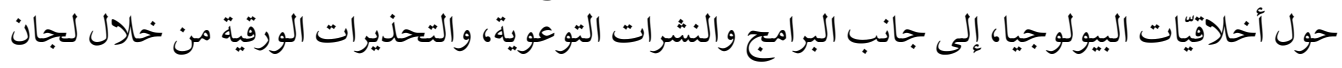

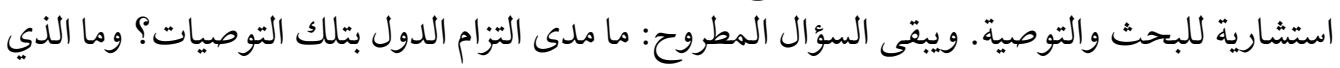

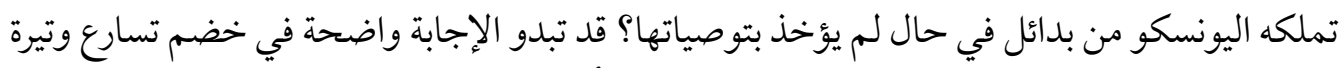

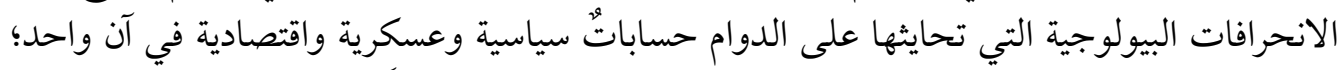
ما أدى إلى تحويل العلم من غاياته الإنسانية النبيلة، إلى آلة قتل متطورة جئَّا.

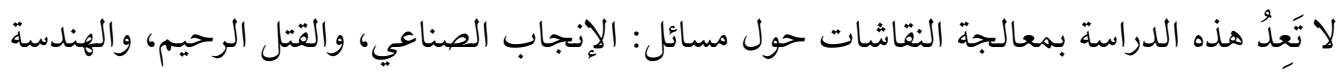

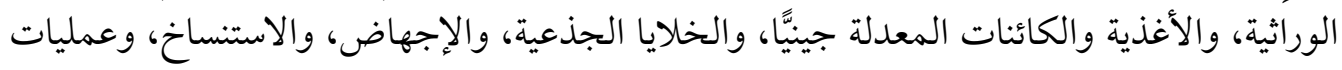

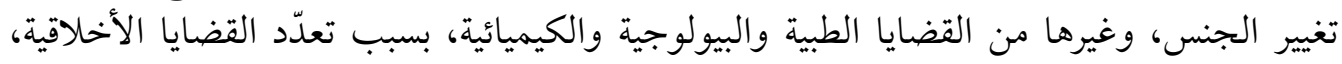

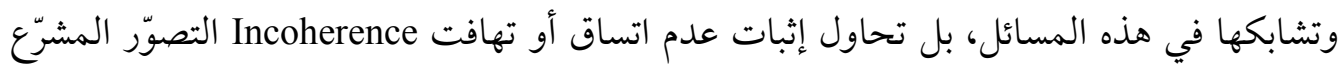

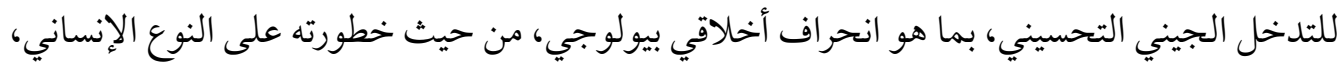

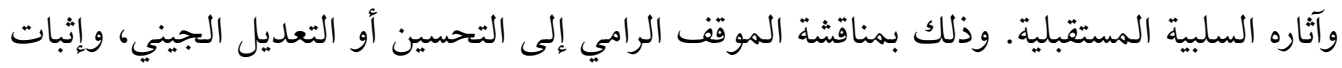

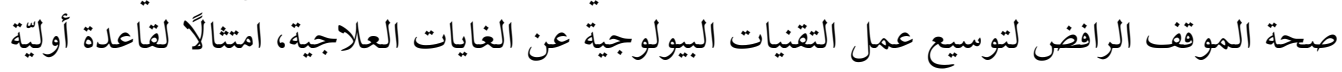

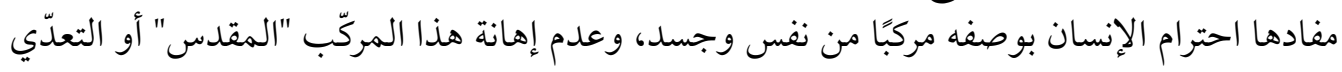

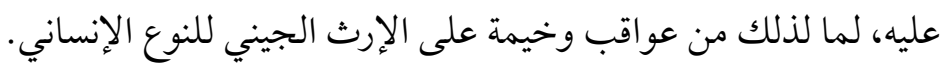

\section{أولًا: أخَلاقِيات البيولوجيا: أزمة المقهومر والتأسيس}

يعود الفضل في انطلاق اصطلاح Bioethics (أخلاقيات البيولوجيا) إلى عالم الكيمياء الحيوية والباحث

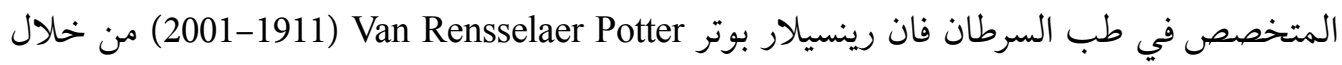

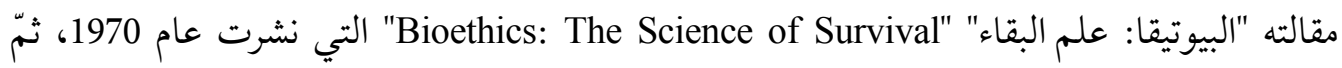

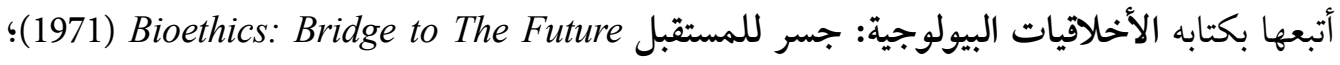


ليؤكد ضرورة أن تكون أخلافيّات البيولوجيا جسرًا لمستقبل آمن للحياة البشرية، من خلال محاصرة التقدم

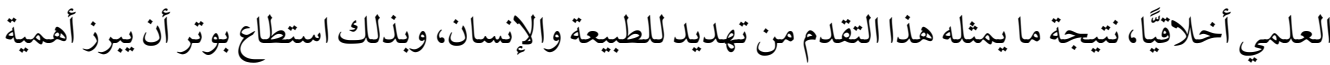

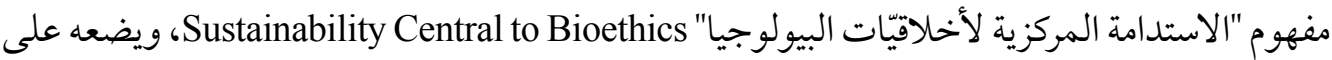

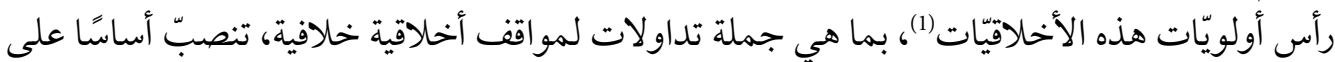
الآثار الناجمة من التطورات البيولوجية والطبية التي كشفت التفاوت بين هذه التطورات العلمية، وبين الفكر الأخلافي الكالاسكي (ولذلك أعلن تأسيس علم جديد: علم النم البقاء أو الاستمرار على قيد الحيد الحياة،

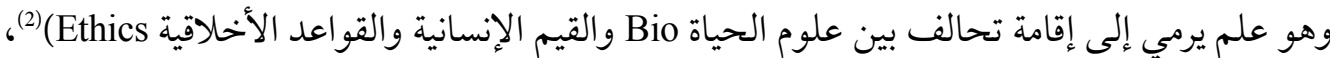

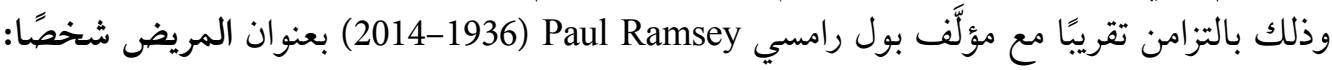

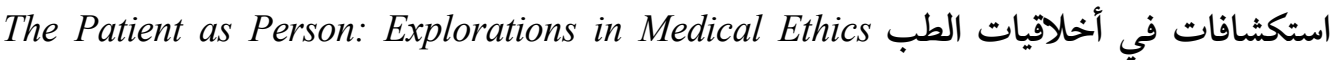
(2006)، وهي دراسات سبَّاقة، أنذرت بقيام انحرافات للعلوم البيولوجية والطبية، قد تشمل خطورتهات

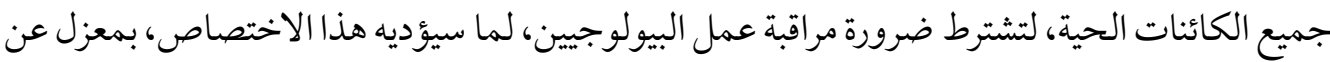

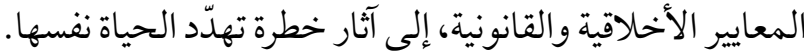

لا يخفى على أحد اليوم تأثير الفكر العلموي Scientism والتقاني، ولا سيما في علم البيولوجيا،

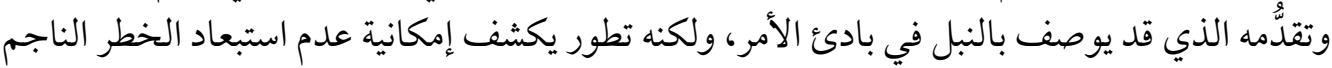

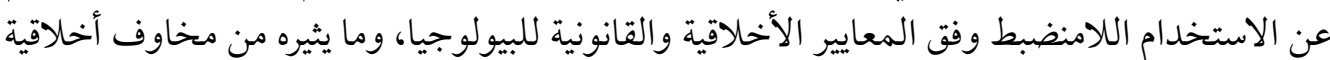

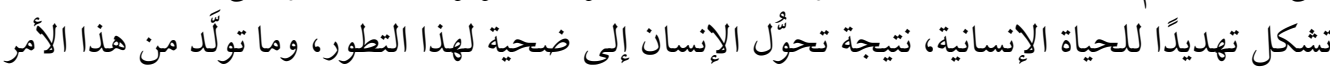

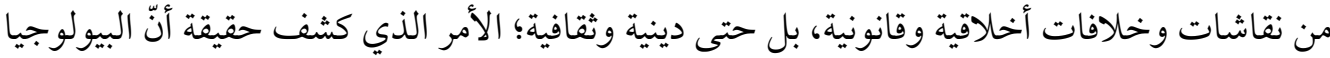

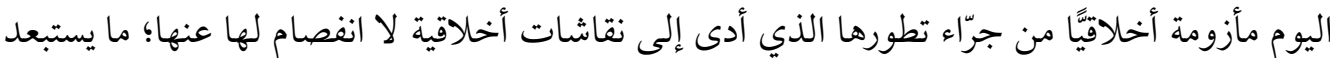

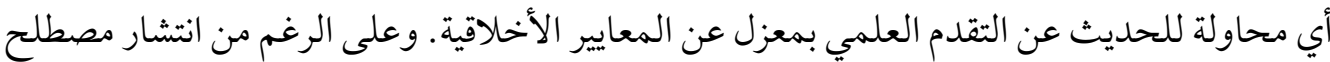

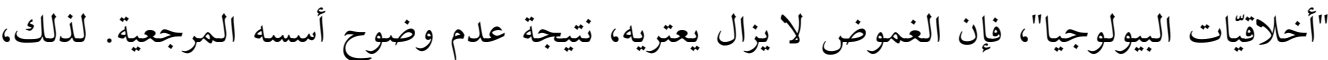

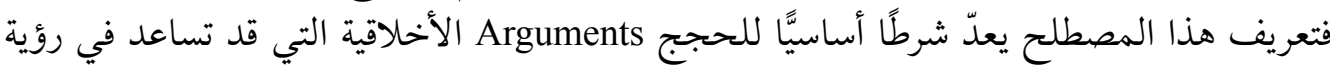
الجوانب المختلفة للقضايا المتعلقة بالممارسة البيولوجية، وإيجاد لغة مشتركة قائمة على الحقائق والقيم Values. فالتعريف "الجيّد" هو عمل أساسي عند الانخراط في الجدل الأخلاقي، لأنه يقوم

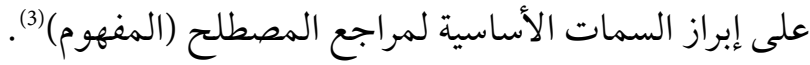
وانطالاقًا من هذا التحديد، يقدّم بيتر ألبرت ديفيد سنجر Peter Albert David Singer تعريفًا وصفيًّا Descriptive المثارة في الرعاية الصحية والعلوم البيولوجية، بما في ذلك القضايا الاجتماعية والقانونية والاقتصادية المتعلقة بهذه القضايا الأخلاقية. وإلى جانب هذا التعريف الوصنيه الوصي، يمكن تقديم تعريف إلزامي

(1) Mary C. Rawlinson, "Bioethics: A bridge to the future," in: Daniel Callahan et al., Global Bioethics: What for? (Paris: The United Nations Educational, 2015), p. 31.

$$
\text { عمر بوفتاس، "البيو إتيقا: نحو فكر أخلاقي جديد"، دفاتر فلسفية، العدد } 9 \text { (2015)، ص 7-8. }
$$

(3) Sirkku K. Hellsten, "Why 'Definitions' Metter in Defining Bioethics?" in: Tuija Takala et al., Cutting Through the Surface: Philosophical Approaches to Bioethics (Amsterdam: Editions Rodopi, 2009), p. 10. 
لهذه الأخلاقيات، ينص على أن يكون الهدف منها النظر في كيفية الحفاظ على كرامة

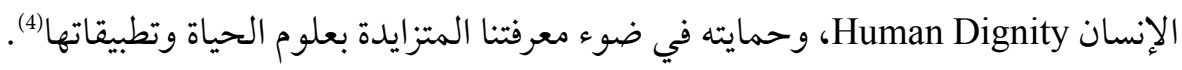

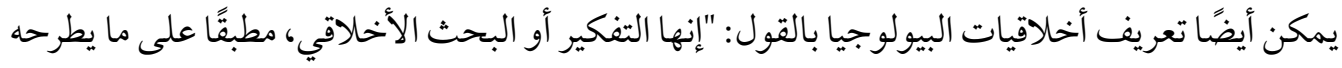

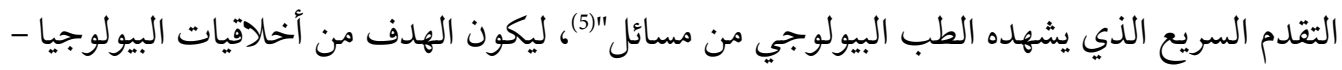

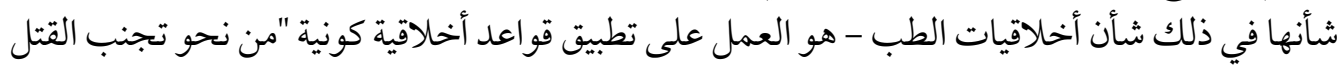

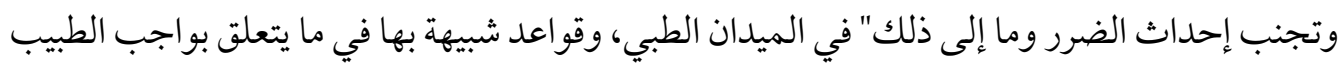

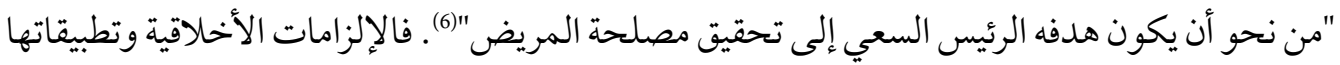

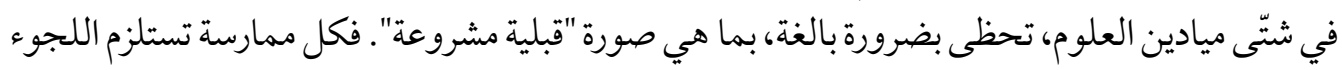

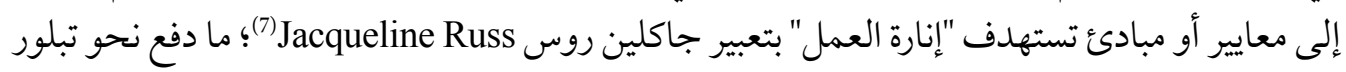

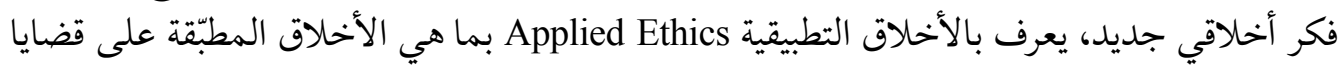

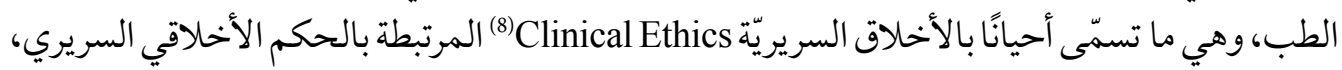

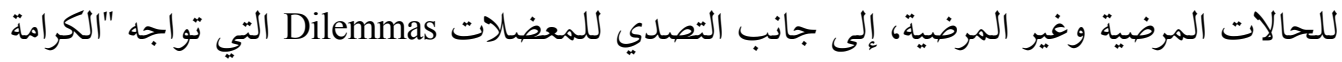

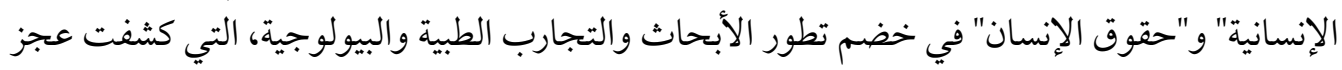

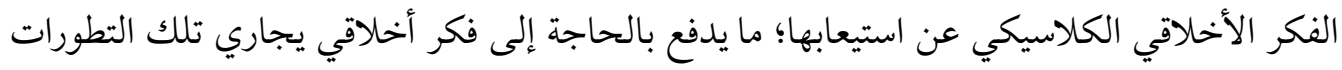

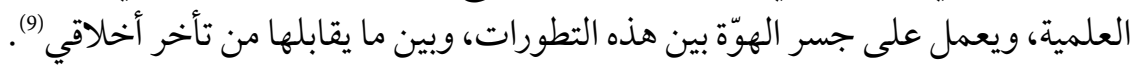

تُعََّف الأخلاق التطبيقية - السريريّة بأنها دراسة لمجموعة من المعضلات الأخلاقية المثقلة بالقيم

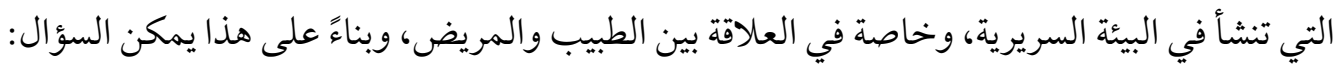

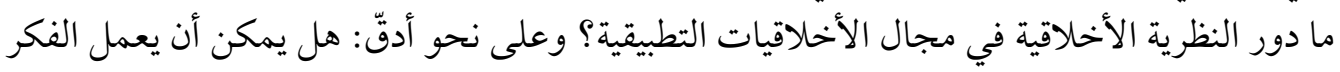

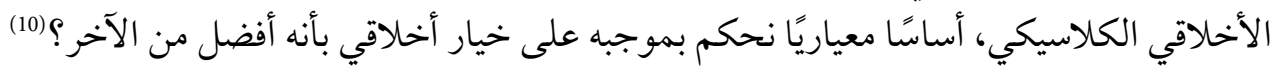

يصر البراغماتيون Pragmatism على ربط الأخلاق بواقع التجربة الحيّة للكائنات البشرية المرتبطة

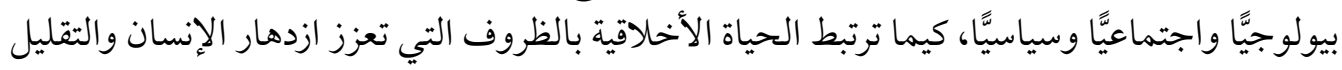

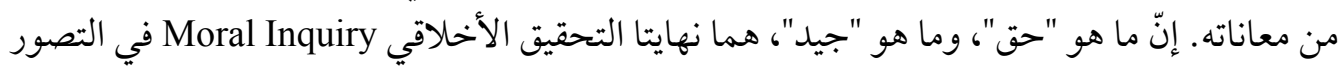

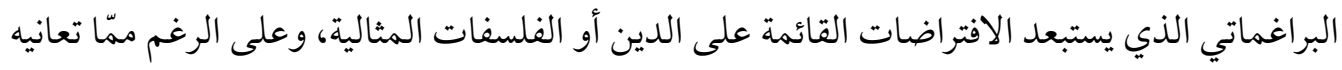

(4) Ibid., p. 11.

(5) بيير أندريه تاغييف، "أخلاقيات البيولوجيا: نحو مشروع قضية فكرية"، ترجمة عبد الهادي الإدريسي، مجلة دفاتر الشمال،

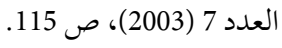

$$
\text { المرجع نفسه. }
$$

(7) ينظر: جاكلين روس، الفكر الأخلاقي المعاصر، ترجمة عادل العوا (بيروت: عويدات للنشر والطباعة، 2001)، ص 108.

(8) David Thomasma, "Aristotle, Phronesis, and Postmodern Bioethics," in: Mark G. Kuczewski \& Ronald Polansky (eds.), Bioethics: Ancient Themes in Contemporary Issues (Cambridge: The MIT Press, 2000), p. 67.

$$
\text { ينظر: بوفتاس، ص 5-6. }
$$

(10) Wayne Shelton, "The Role of Empirical Data in Bioethics: A Philosopher's View," in: Liva Jacoby \& Laura A. Siminoff, Empirical Methods for Bioethics: A Primer, vol. 11 (Amsterdam: JAI Press, 2008), p. 13. 
الأخلاق اليوم من نسبية Relativism، وأزمة في مفهوم القيمة الأخلاقية، فإنّ البراغماتيين يعتقدون

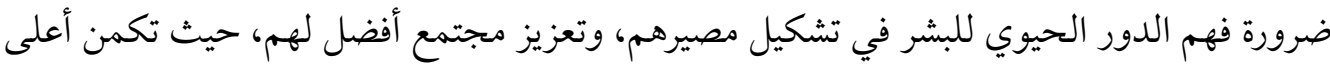

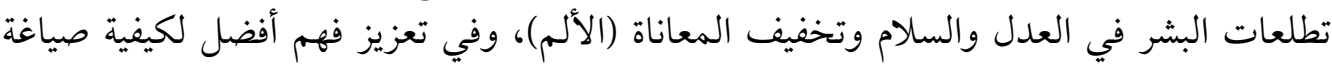

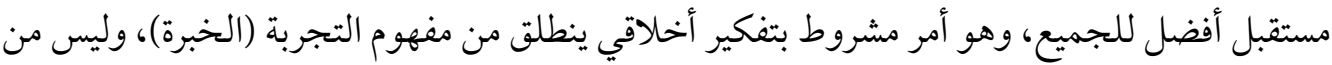

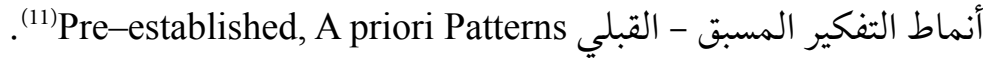

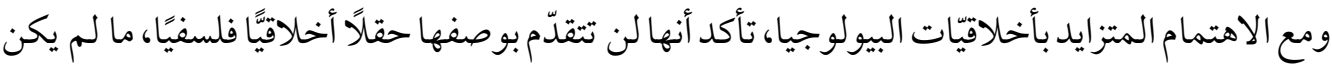

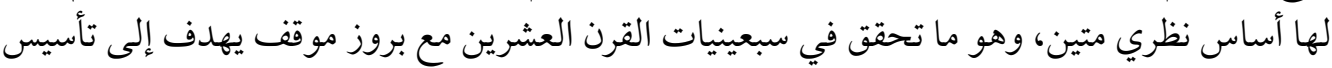

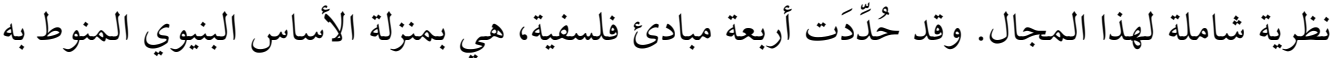

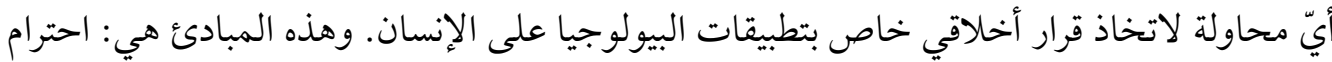

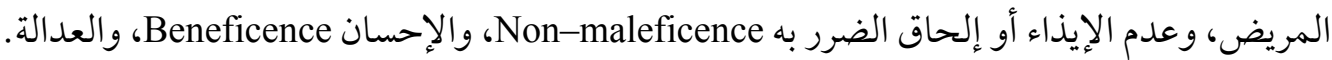

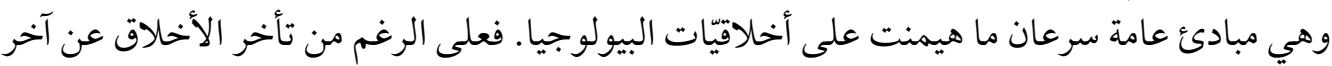

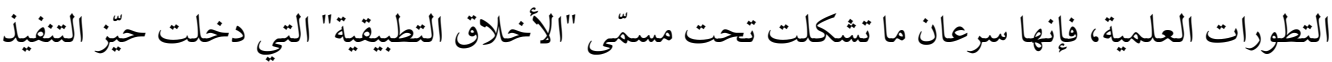
بو صفها محاولة للجمع بين التحليل الفلسفي والأدلة التجريبية (12). في هذا السياق، يرى جون أراس John Arras أن ثمّة العديد من المختصين في أخلاقيّات البيولوجيا،

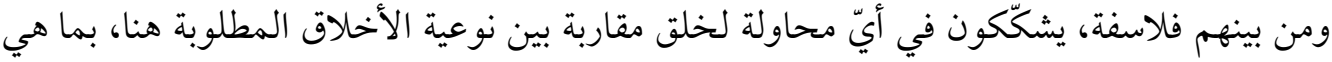

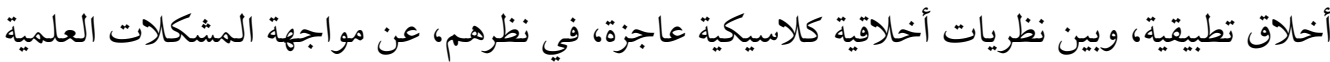

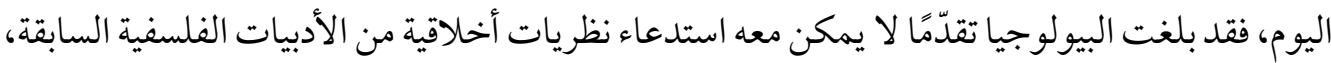

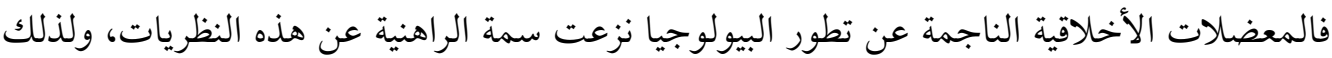

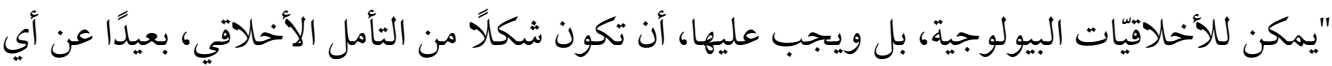

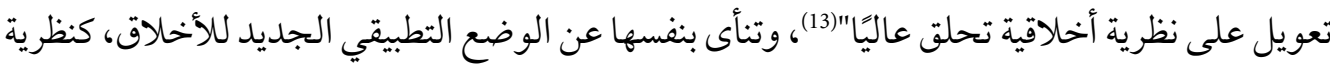

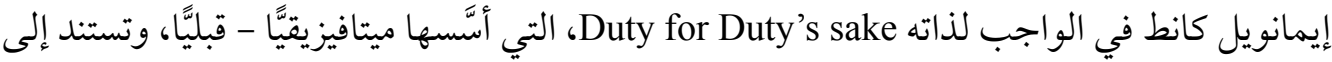

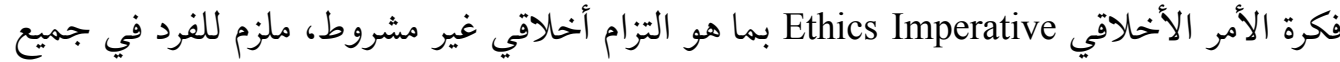

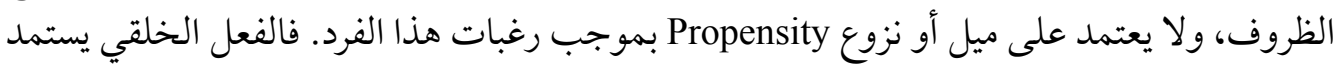

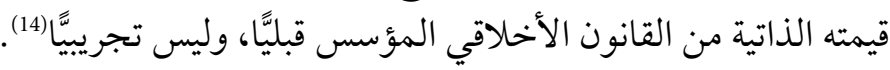

ولكن، ومن أجل الحصول على تفسيرات قابلة للتطبيق في مجال أخلاقيّات البيولوجيا، يرى أنصار

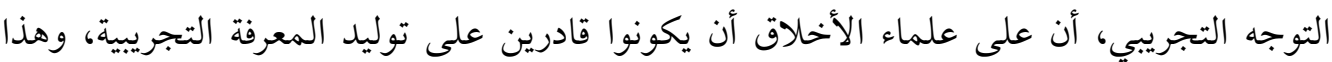

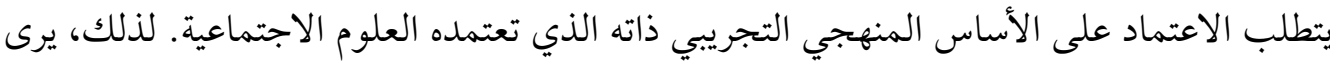

(11) Ibid., p. 15.

(12) Daniel Callahan, "Bioethics: Its Past and Future," in: Callahan et al., pp. 20-21.

$$
\text { جون أراس، "النظرية والبيو إتيقا"، ترجمة شيماء عطية وأحمد فاروق، دفاتر فلسفية (2015)، ص 33-34. }
$$

(14) Immanuel Kant, Groundwork for the Metaphysics of Morals, Allen Wood (trans.) (New Heaven: Yale University Press, 2002), p. 88. 
بعض ممثلي الأخلاق التطبيقية أن النظرية الأخلاقية لم تعد اليوم معزولة عن التجربة، كما هو حال

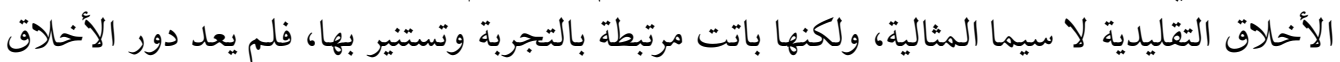

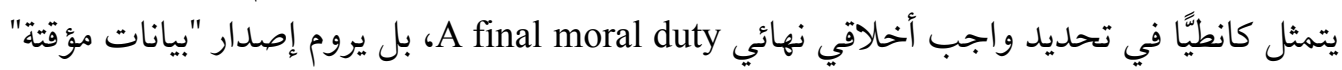
إجابات عrovisional Statements

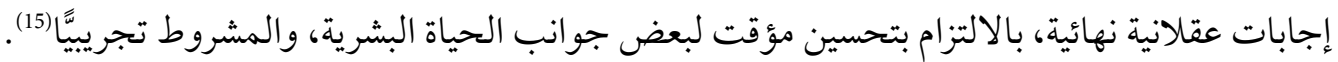

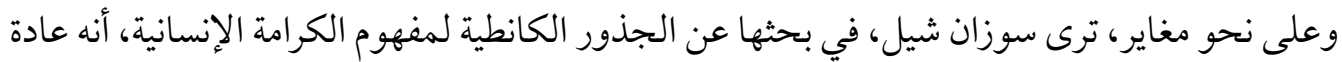

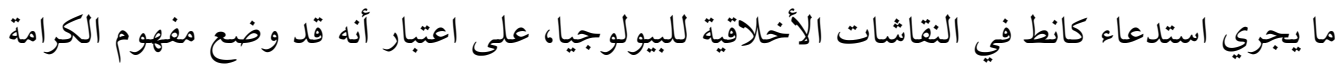

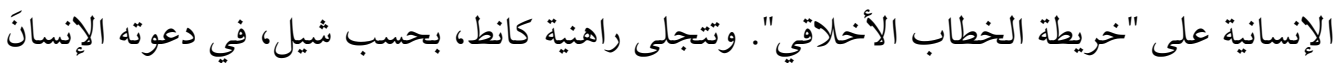

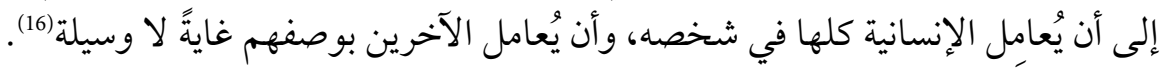

حاول كانط مأسسة Foundation مفهوم عقلاني صرف Strictly Rational لكرامة إنسانية

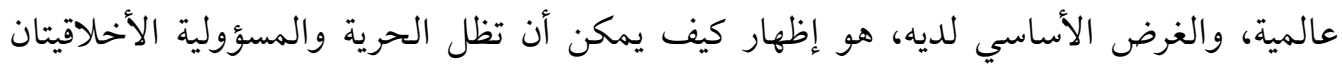

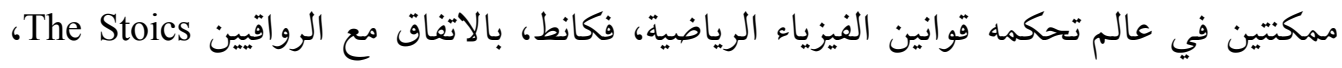

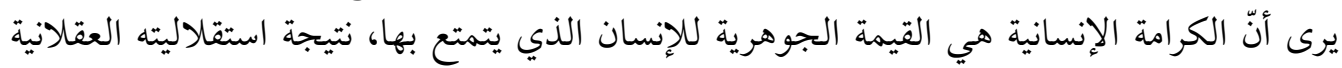

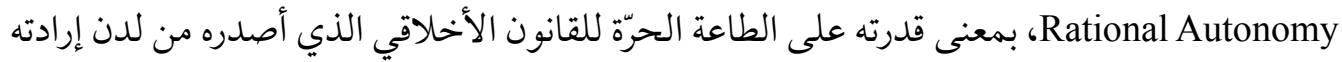

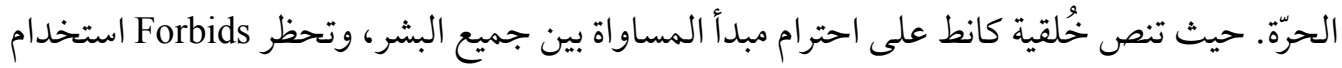

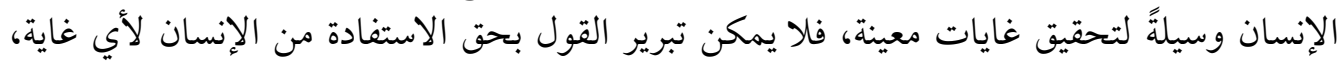

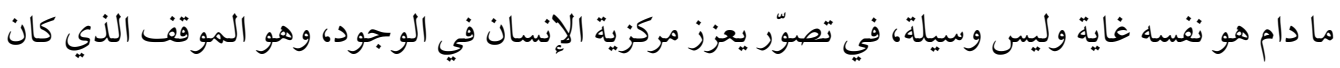

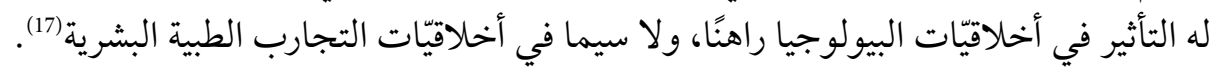
ومع ذلك، يرى آدم شولمان أنّ محاولة تطبيق نظرية كانط الأخلاقية على أخلاقيّات البيولوجيا تواجه

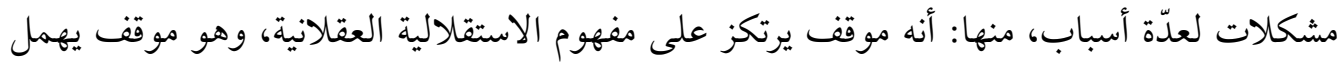

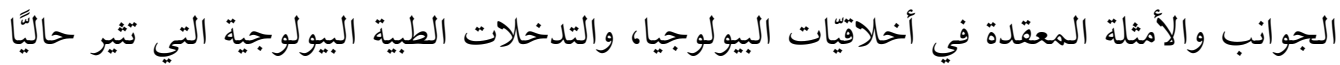

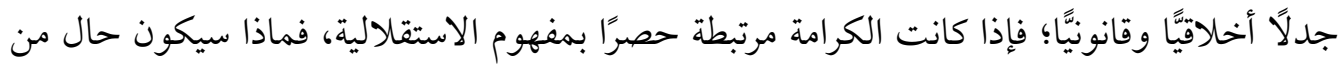

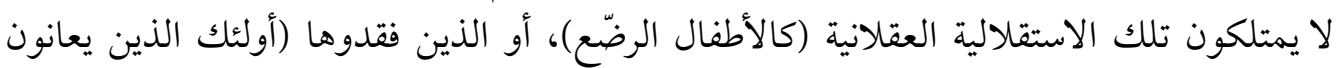

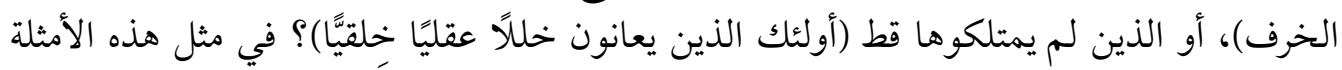

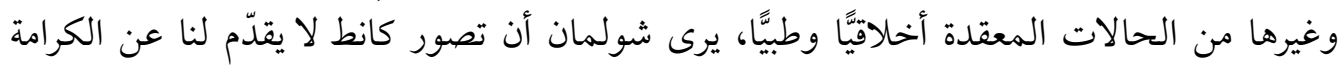

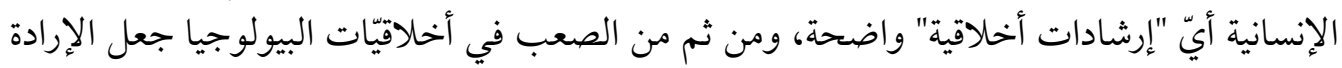

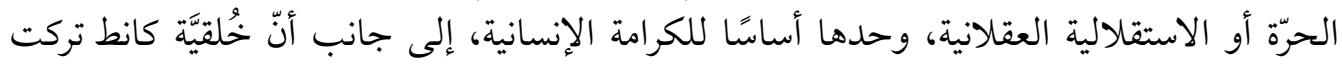

(15) Jacoby \& Siminoff, pp. 15-16.

(16) Susan Shell, "Kant's Concept of Human Dignity as a Resource for Bioethics," in: Adam Schulman et al., Human Dignity and Bioethics, Essays Commissioned by the president's council on Bioethics (Washington, DC: The President's Council on Bioethics, 2008). pp. 334-336.

(17) Adam Schulman, "Bioethics and the Question of Human Dignity," in: Schulman et al., p. 10. 
تمييزًا صارمًا بينها وبين أخلافيّات المنفعة Utilitarianism التي تتمسّك بتلابيب آثار الفعل ونتائجه.

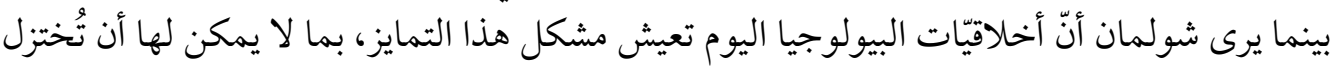

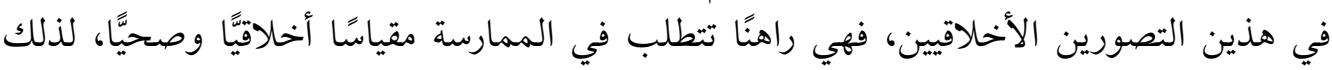

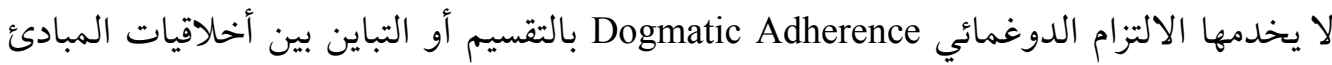

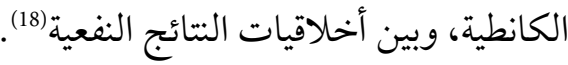

إنّ البحث عن معايير أخلاقية تطبيقية تتسم بالكونية هو ميدان عمل أخلاقيات البيولوجيا لحفظ

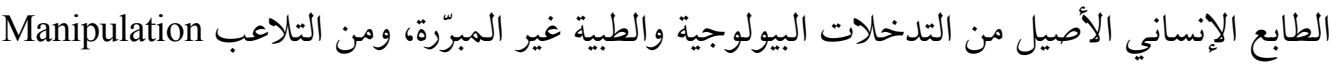
بخصائص الإنسان الوراثية، بما هو نزوع علمي نحو التحكي التحم والسيطرة حدّ التغيير في النوع الإنساني.

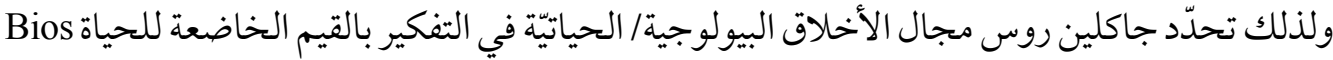
(تعني حياة باللغة الإغريقية)، أو تدل على الميتا-أخلاق Metaethics ("ما وراء الأخلاق")(19).

يمكن تقديم وصف أوتفريد هوف Otfried Hoffe، إذ يقول: "إن مجال اهتمام أخلاقيات البيولوجيا

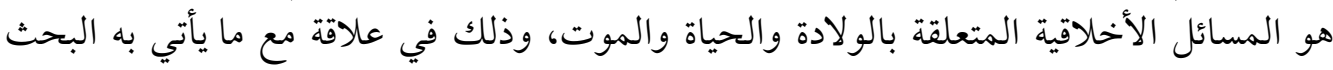

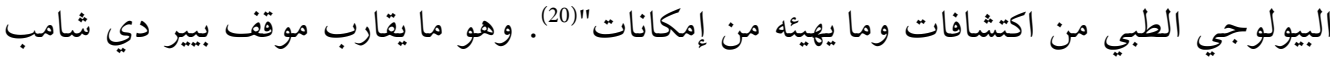

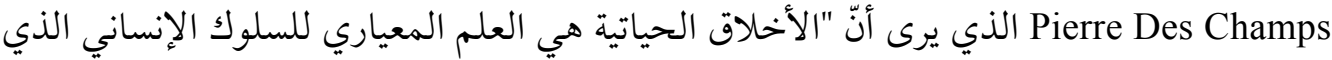

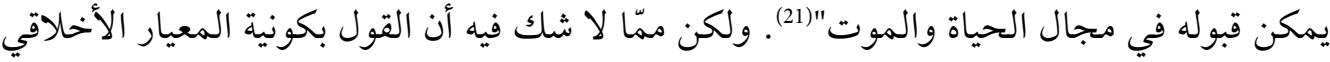
يواجه صعوبة بالغة، نتيجة المؤثرات الثقافية والدينية المختلفة حول العالم لأخلاق البيولوجيا؛

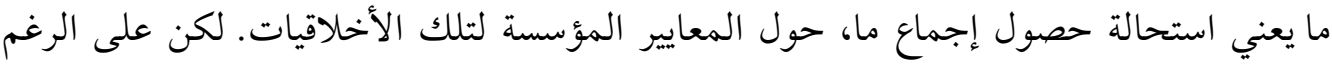

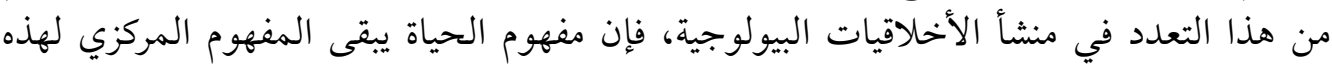

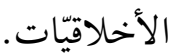

في مواجهة سؤال التعدد أو التنوع في المؤثرات الثقافية لأخلاقيات البيولوجيا، ومطلبها الكوني،

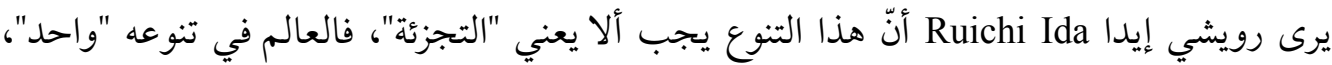
وليس "مجزوءًا"، والبشرية تجمعها "وحدة أو ترابط المصير"، ولا يمكن لفرد أو لدولة الزعم "بالاكتفاء

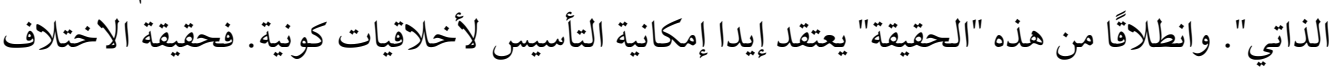

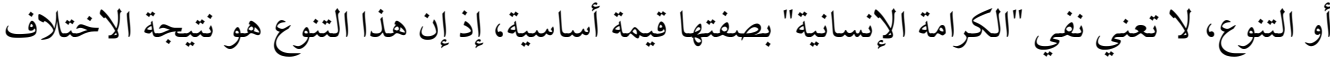

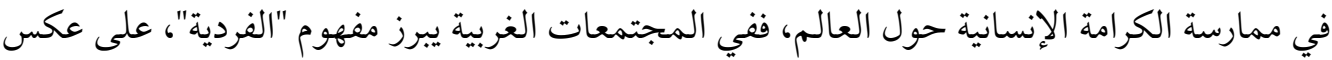

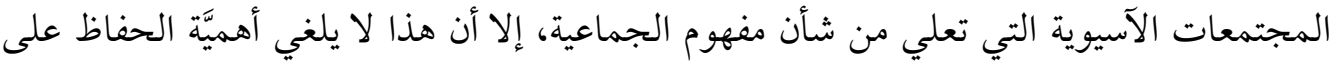

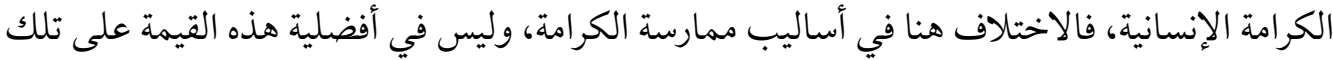

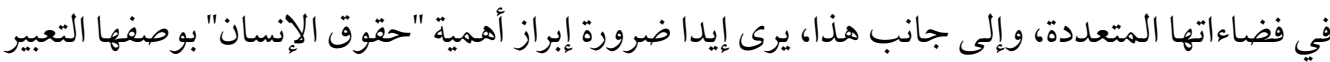

(18) Ibid., pp. 10-12.

روس، ص 110.

تاغييف، ص 115.

روس، ص 111. 
القانوني عن تلك الكرامة الإنسانية، فيحدّد ثلاث ركائز يمكن من خلالها التأسيس لأخلاقيات كونية، هي: التنوع، والمصير المشترك، وحقوق الإنسان (22).

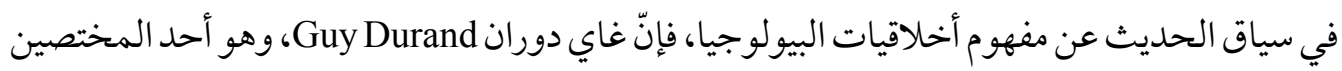

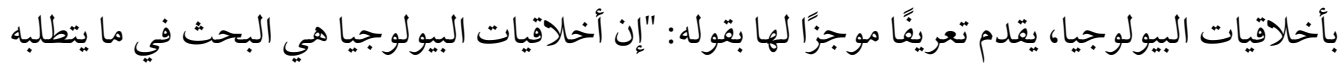

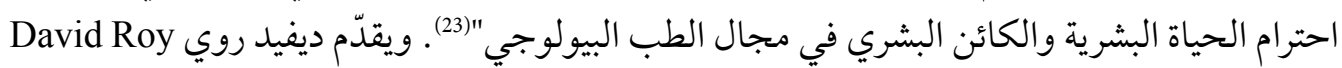

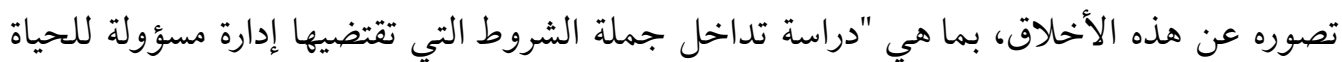
الإنسانية في إطار صنوف التقدم السريعة والمعقدة للمعرفة وللتقانات الحيوية الطبية"(24).

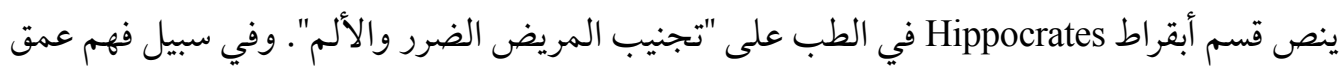

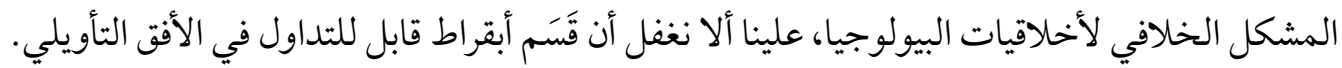

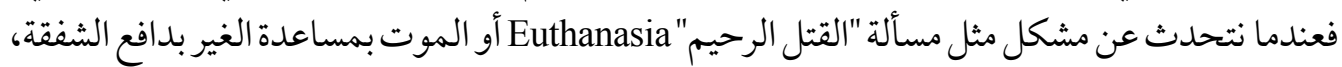

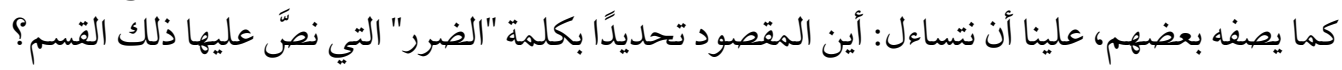

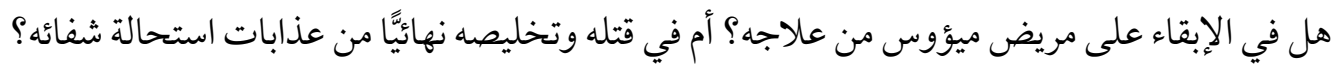
وفقًا لهذا المشكل يمكن التساؤل أخلاقيًَا: ما "الضرر" طبقًا للقاعدة الأبقراطية؟ هل يمكن أن يفهم هنا

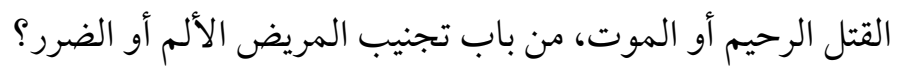

إن هذا المشكل، وغيره من مسائل البيولوجيا والطب، مفتوح على شتى أنواع المؤثرات الثقافية والعرفية

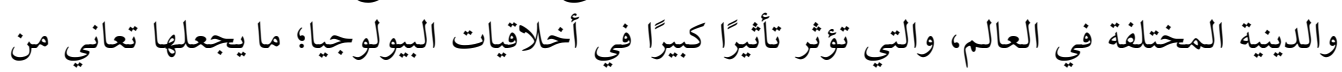

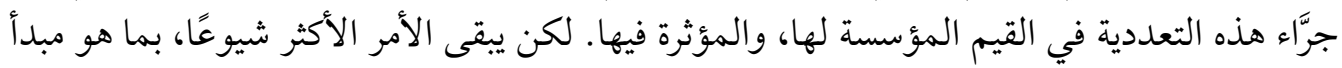

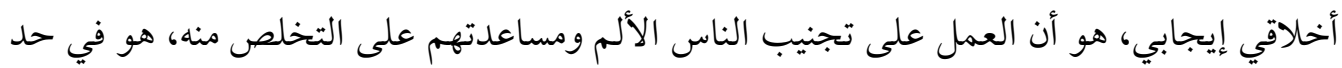

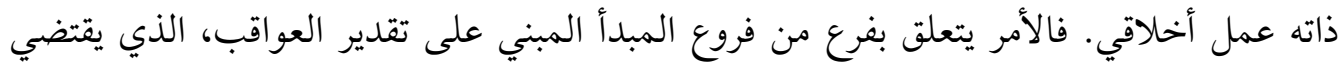

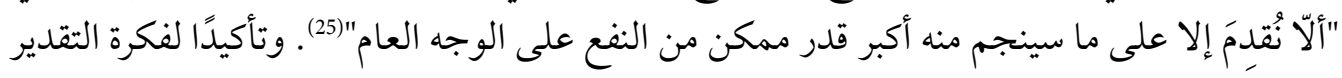

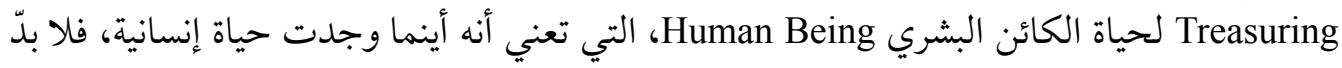

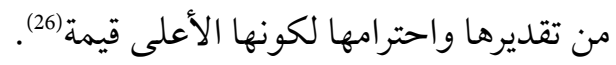

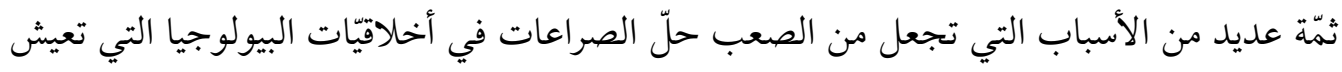

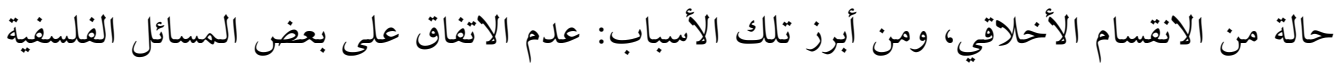

(22) جيروم بيندي [وآخرون]، القيم إلى أين؟ مداولات القرن الحادي والعشرين، ترجمة زهيدة درويش جبور وجان جبور (بيروت:

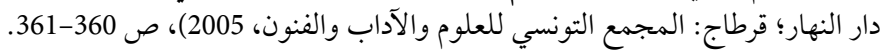

$$
\text { (24) ) تاغيف، ص } 116 \text { (25) }
$$

(26) ناهدة البقصمي، الهندسة الوراثية والأخلاق، سلسلة عالم المعرفة 174 (الكويت: المجلس الوطني للثقافة والفنون والآداب، 


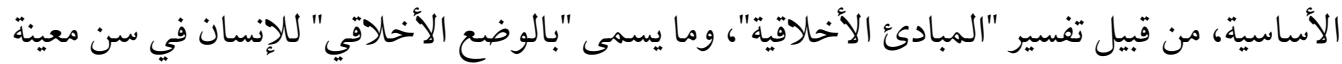

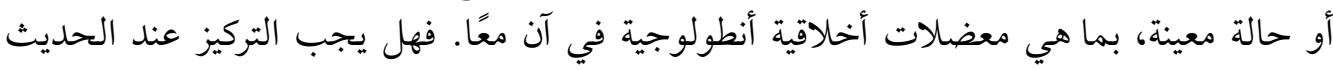

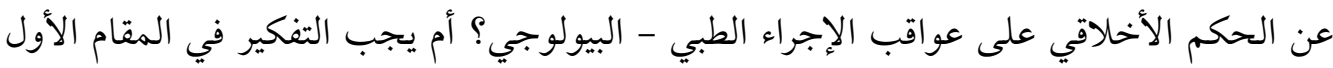

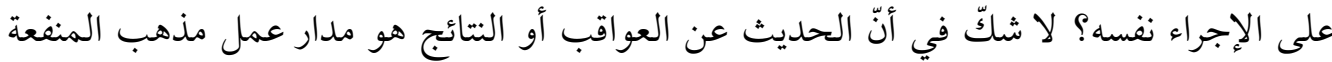

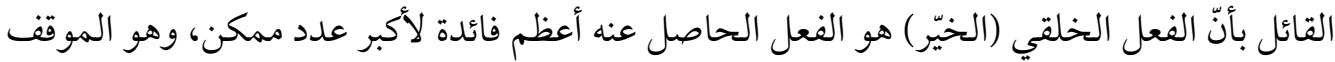

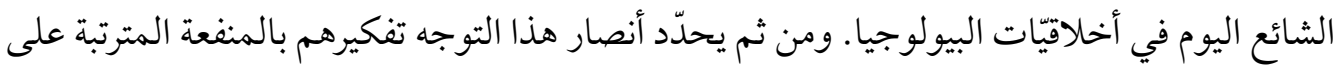

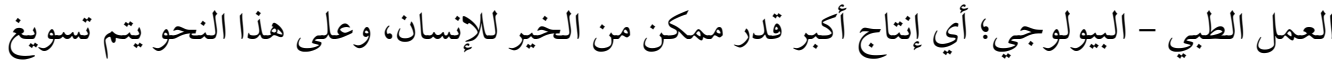

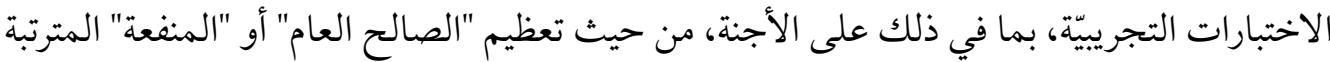

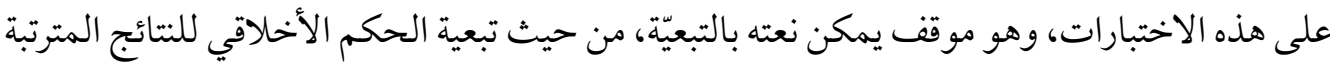

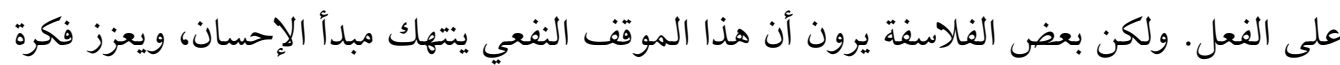

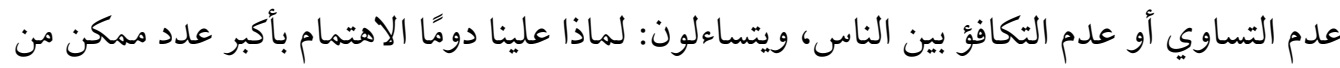

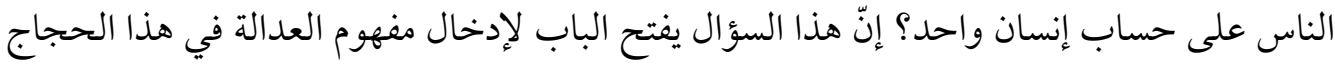

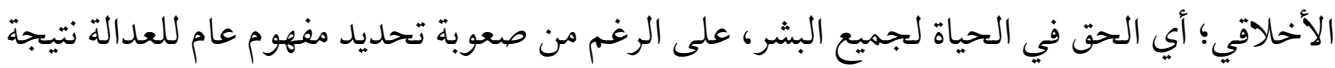

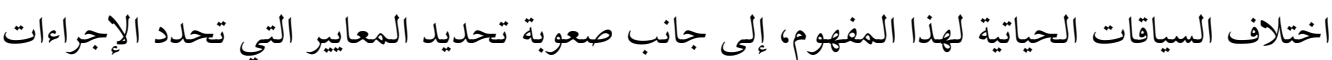

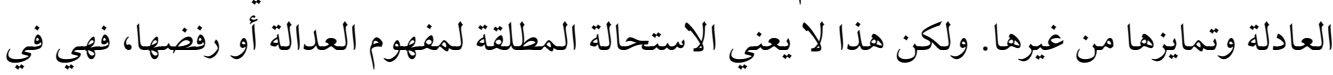

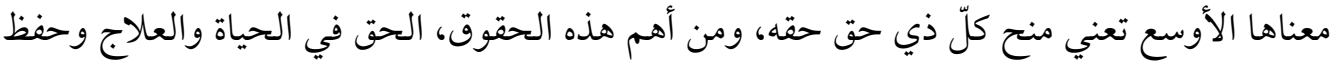

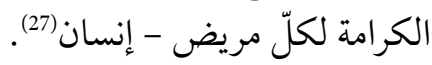

على الرغم من تعدّد المعايير المؤسسة لأخلاقيَّات البيولوجيا، فإنه بحسب بيير-أندريه تاغييف Pierre-Andre Taguieff

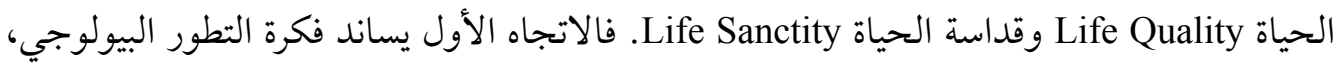

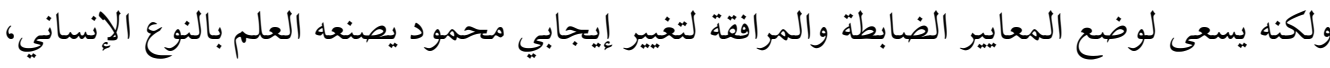

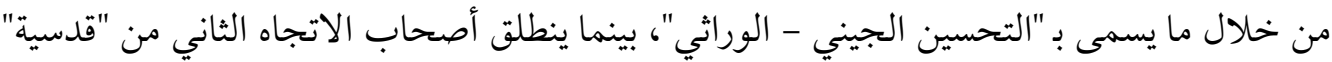

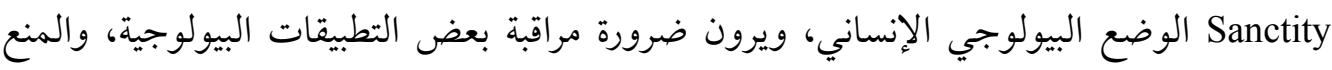

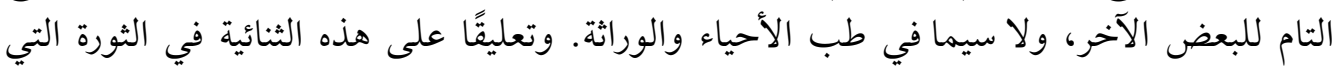

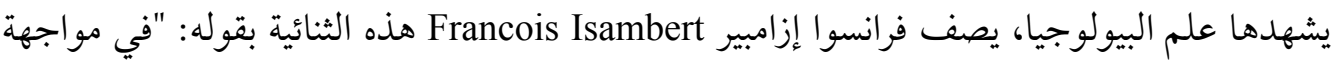

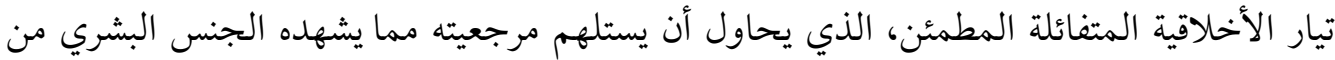

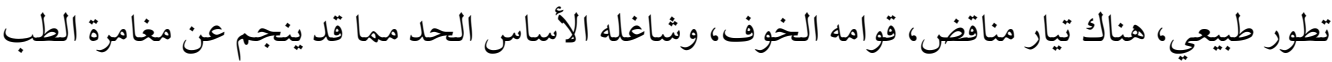

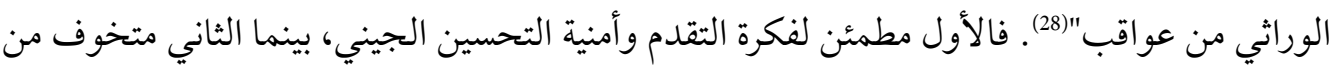
فكرة التقدم نفسها، لما للوضع البيولوجي للإنسان من قداسة تحول دون التلاعب بهذا التهن الوضع.

(27) Alfonso Gomez Lobo \& John Keown, Bioethics and the Human Goods: An Introduction to Natural Law Bioethics (Washington, DC: Georgetown University Press, 2015), pp. 15-17. 


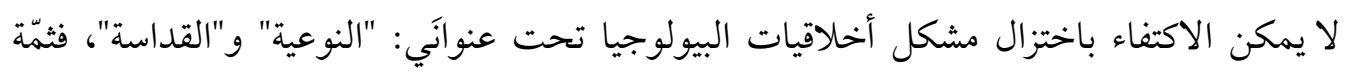

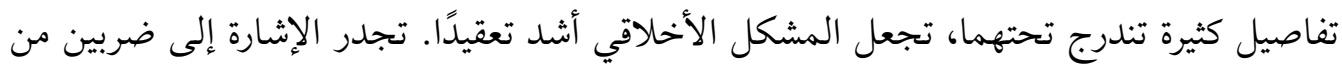

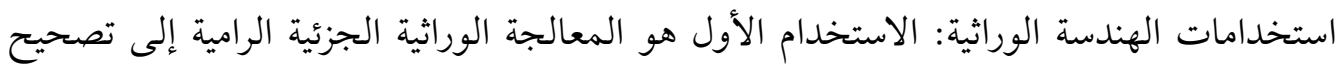

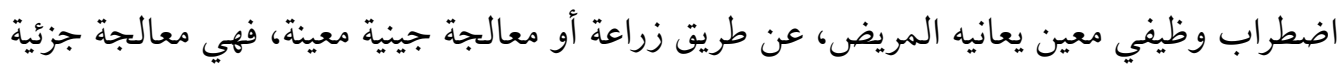

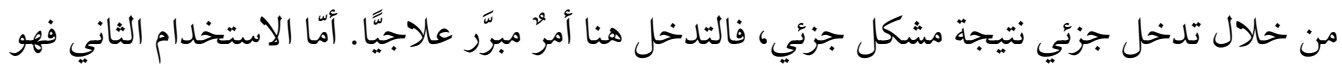

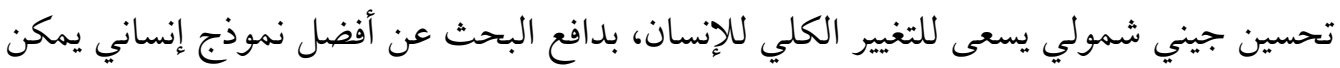

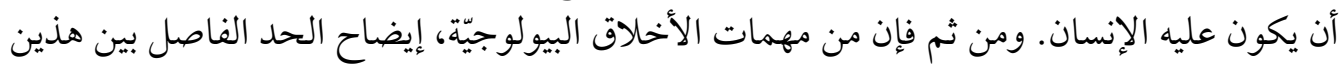
الاستخدامين للهندسة الوراثية، والوقوف في وجه أدعن منياء سياسة تحسين النسل (29).

يوضح يورغن هابرماس Jurgen Habermas موقفه من التقنية الجينية التي يراها مقبولة أخلاقيًّا وقانونيَّا

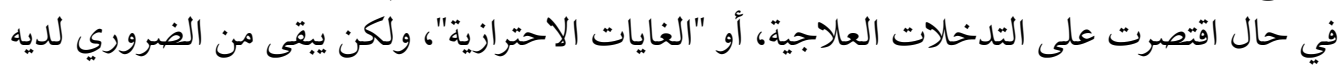

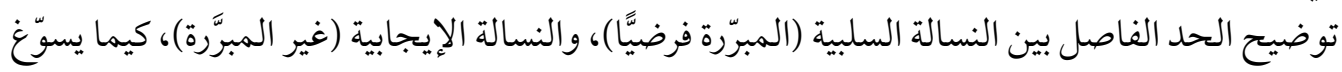

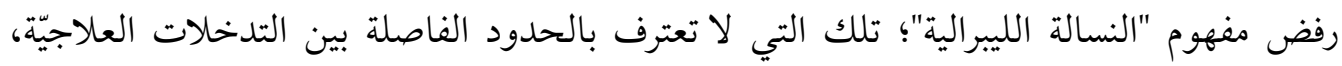

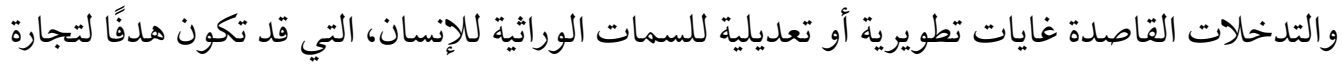

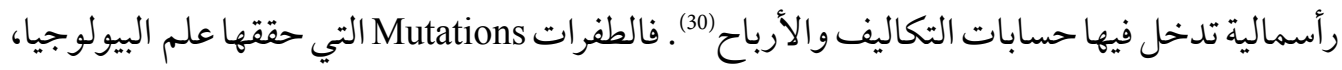

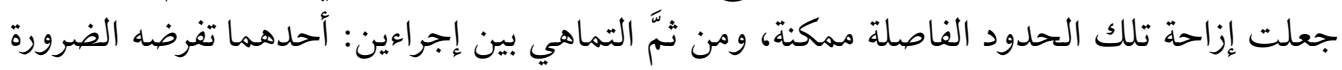

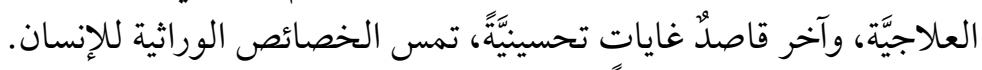

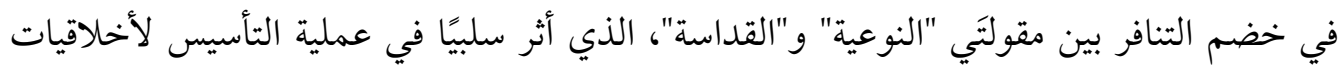

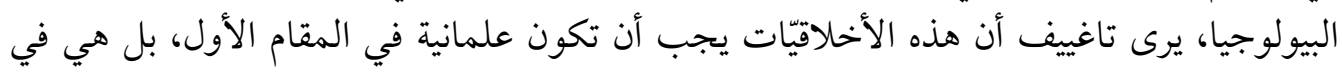

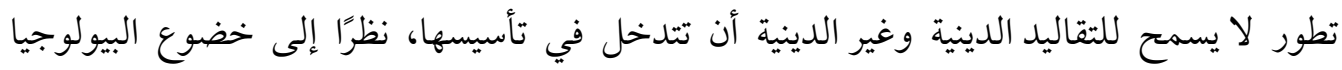

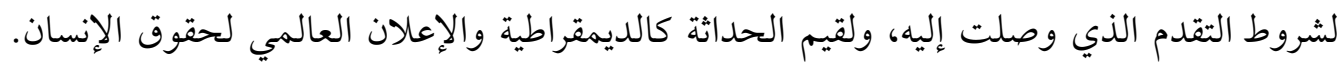

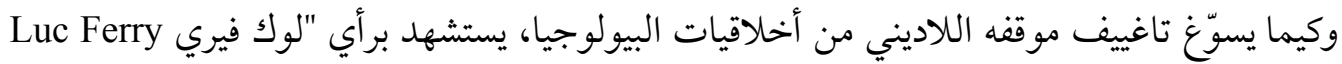

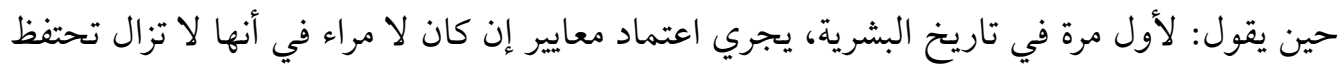

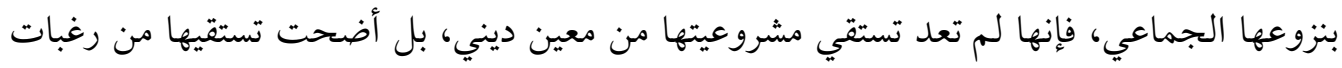

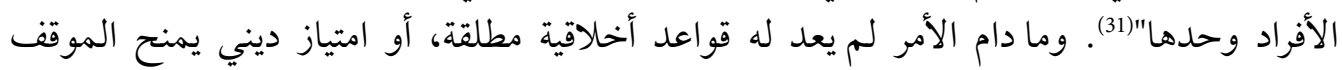

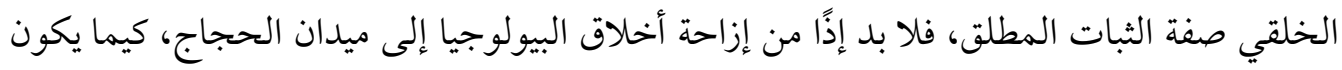

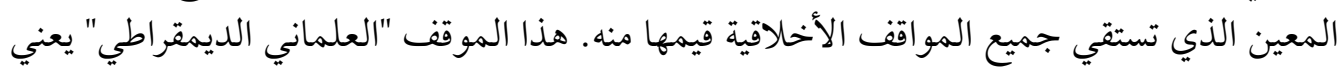

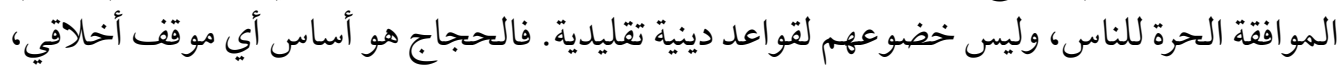

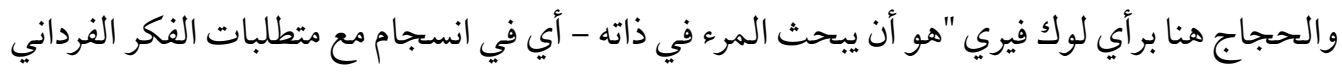

$$
\text { روس، ص } 114 .
$$

(30) يورغين هابرماس، مستقبل الطبيعة الإنسانية: نحو نسالة ليرالية، ترجمة جورج كتوره (بيروت: المكتبة الشرقية، 2006)، 


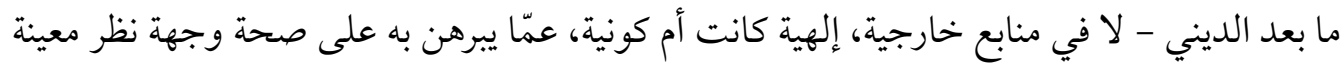

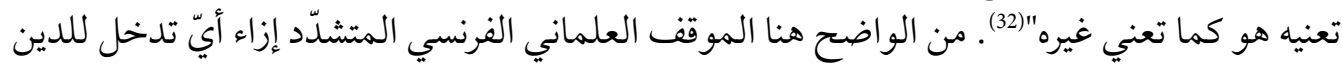

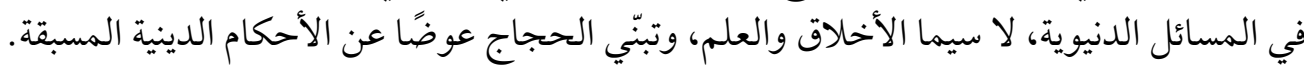
يتوسّل أنصار الموقف الحجاجي - وهو موقف ديمقراطي ليبرالي - بإنهاء جميع النقاشات الأخلاقية

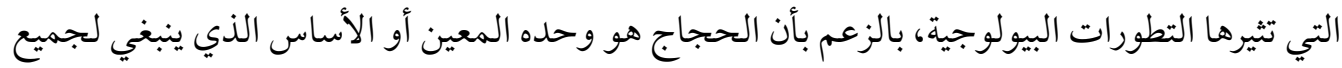

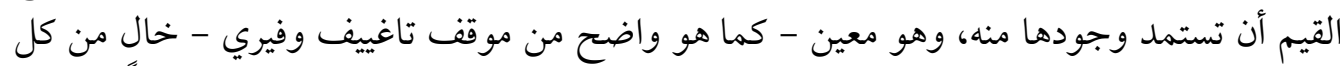

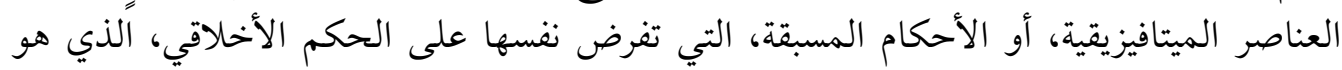

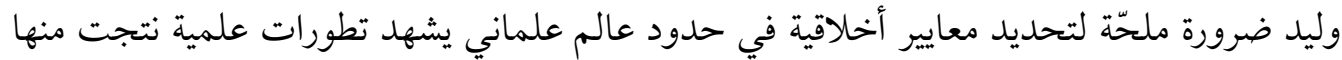

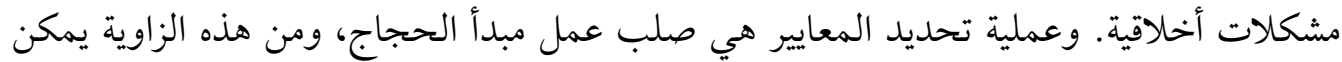

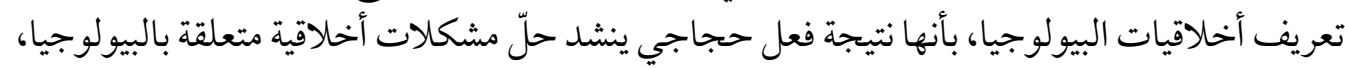

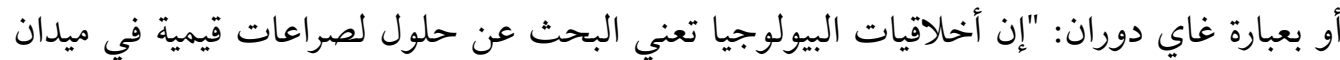

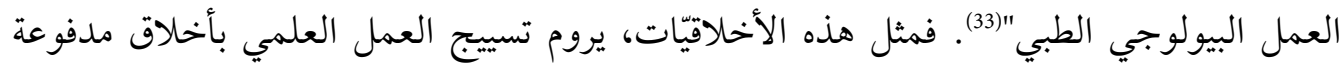

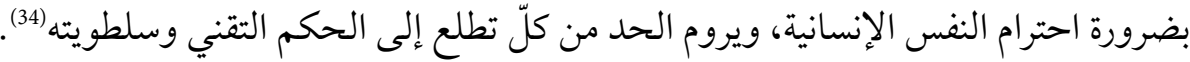

يمكن الحديث، إذًا، عن اتجاهين أخلاقيين، يحاصران تطورات تقنيات العلم على المستوى التطبيقي

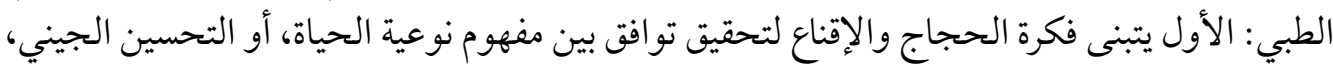

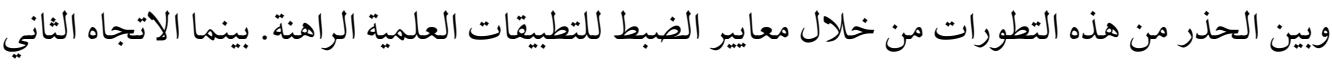

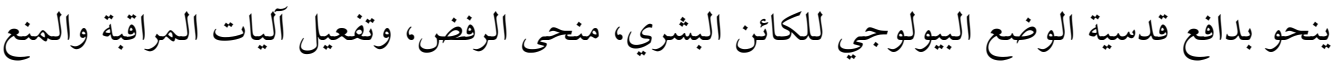

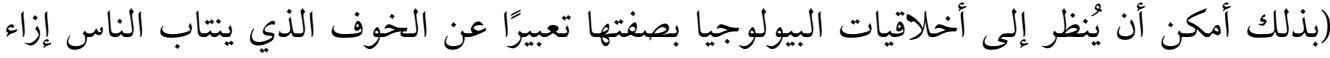

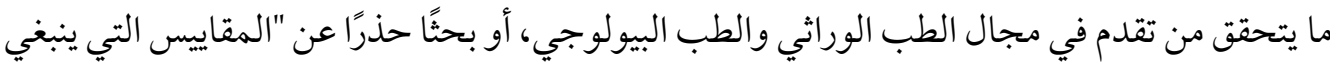

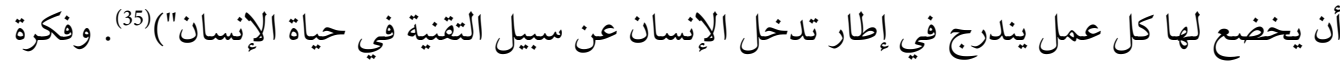

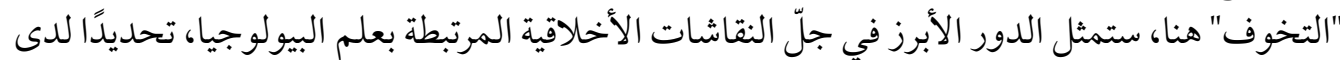

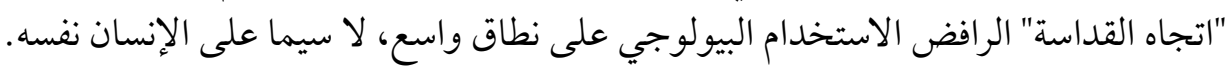

\section{ثُانيًا: العلموية ومـاُّرورعية التحَوف البيولوجي}

في هذا العصر الاستثنائي وغير المسبوق للتقدم البيوتكنولوجي، انتقلت حملة غزو الطبيعة والسيطرة

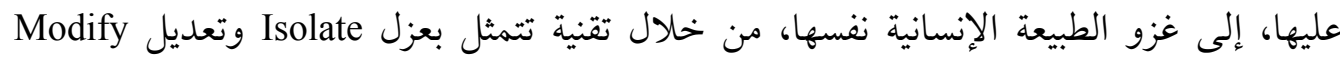

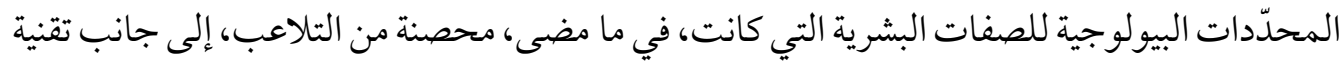
الاستنساخ، وحمل الأجنة البشرية في الأرحام الاصطناعية أو الحيوانية، إضافة إلى الأدوية ذات التئية التأثير 


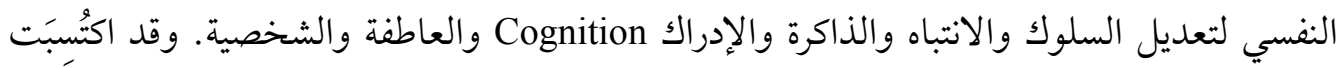

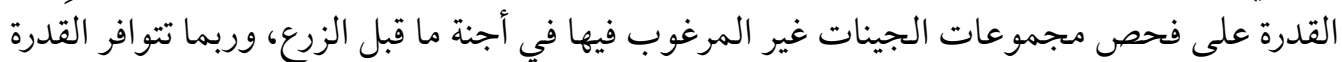

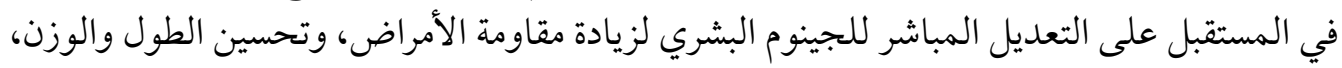

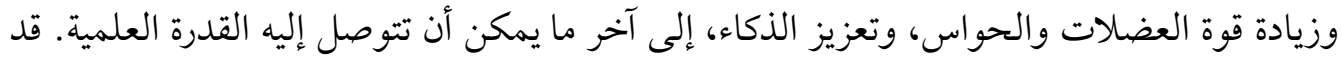

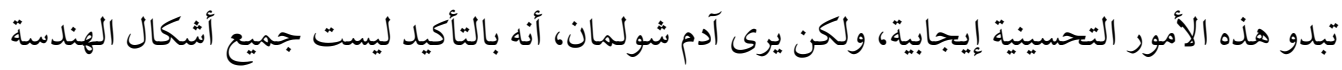
الطبية البيولوجية حميدة Benign ومقبولة على الدوام.

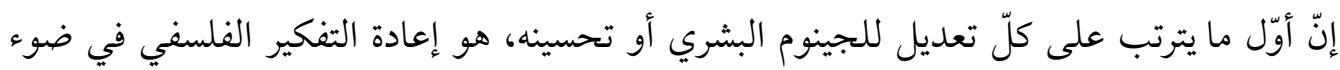

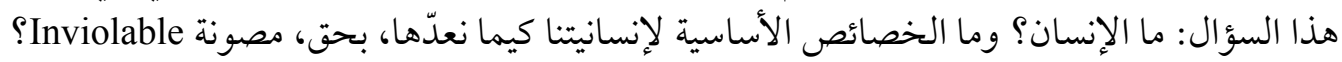

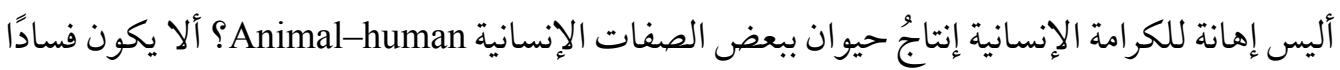

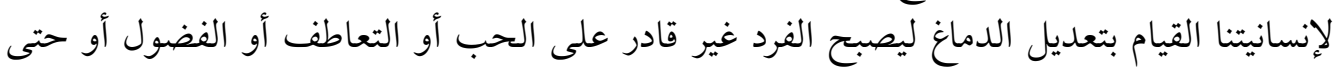

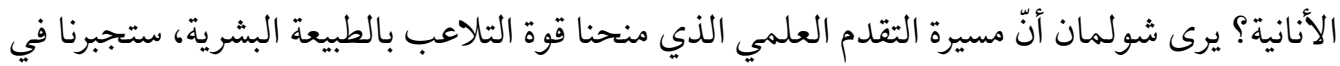

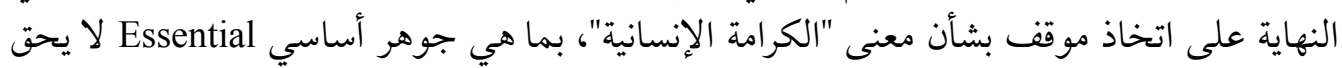

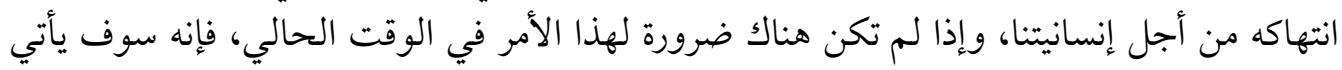

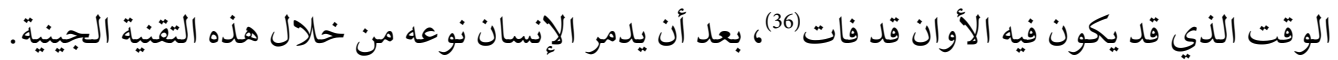

ما حدود المعرفة العلمية؟ سؤال بصيغة كانطية يبادر إليه بيير تاغييف لما له من ارتباطات بيولوجية

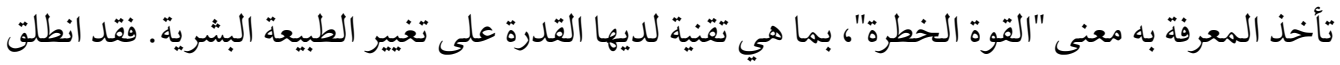

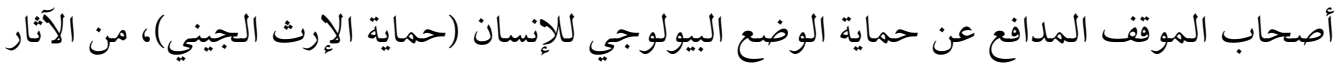

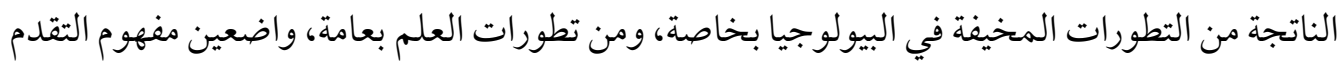

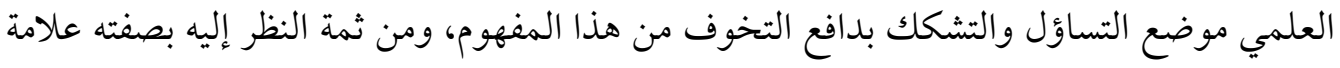

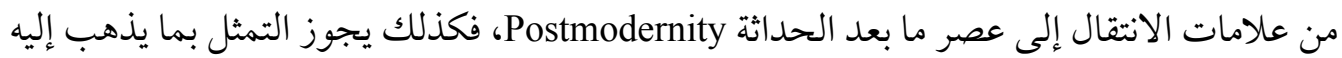

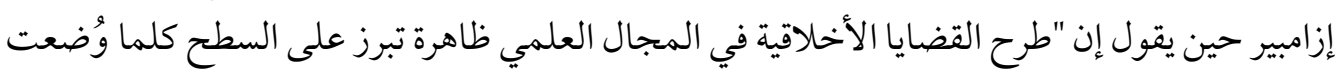

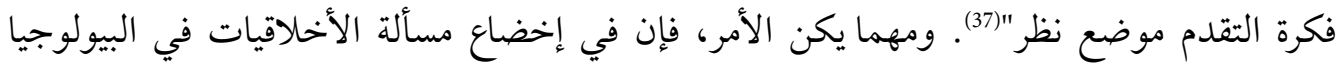

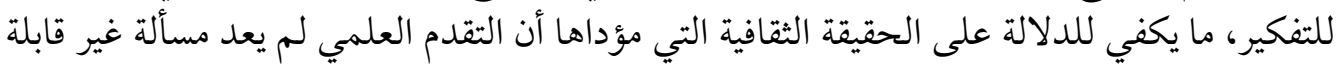

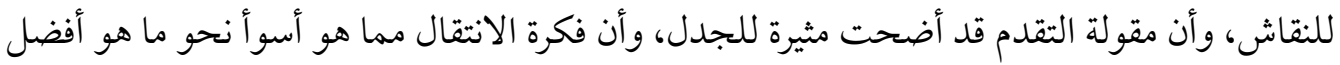

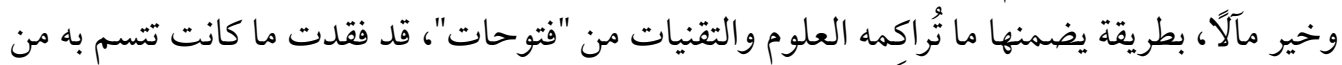
طابع البدهية (38).

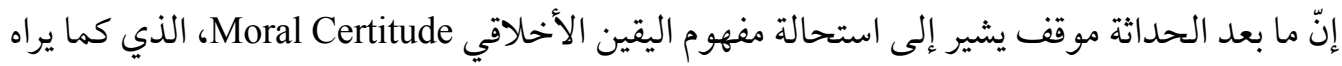

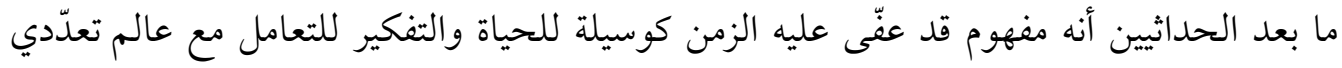
pluralistic world

(36) Schulman, pp. 16-17.

(37) Gilbert Hottois, Evaluer la technique: Aspects éthiques de la philosophie de la technique (Paris: Vrin, 1988), p. 88. 
بالتعددية الأخلاقية والثقافية، لاستحالة وجود معايير شاملة للسلوك أو الأخلاق الموضوعية، فالبحث عن أساس موضوعي للأخلاق، بما هو إحدى مقولات مشروع التنوير، هو، لديهم، أمر قد مات! (39) إنّ كثيرًا من الاقتصاديين، في ما يرى إدوارد أوسبورن ويلسون Edward Osborne Wilson، يتوافقون

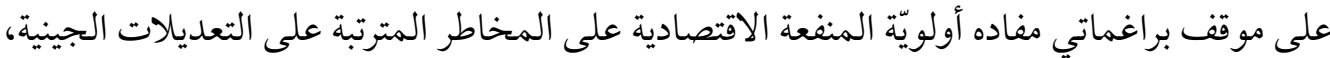

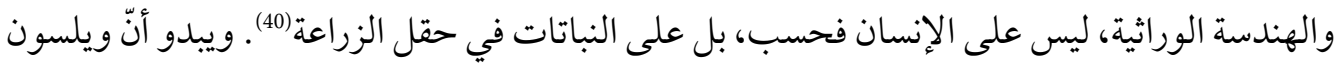

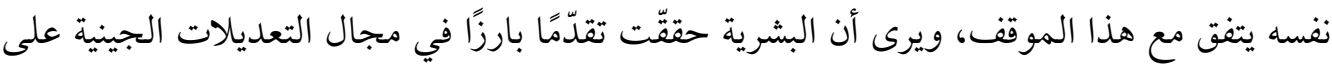
النباتات لتوفير الغذاء للأعداد المتزايدة من البشر في العالم. فالتغييرات الوراثية التي تحرزها البيولوجيا

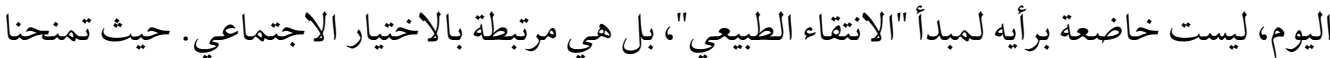

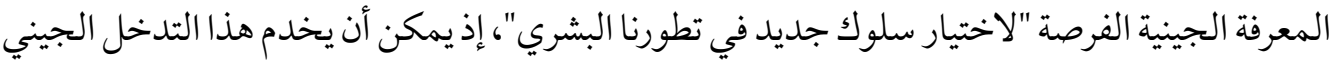

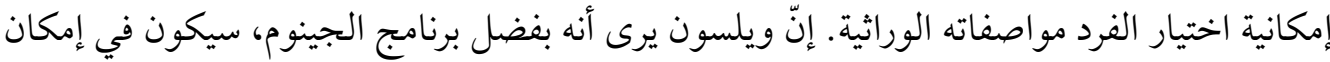

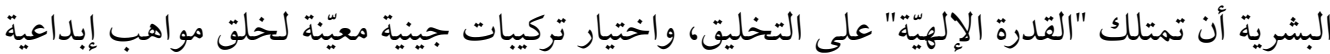

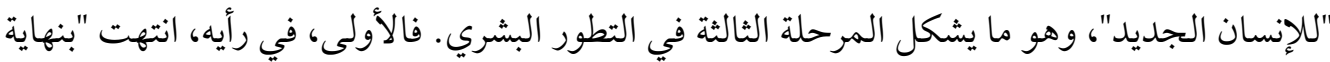

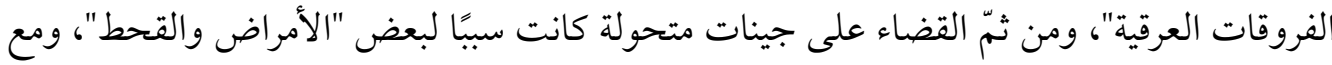

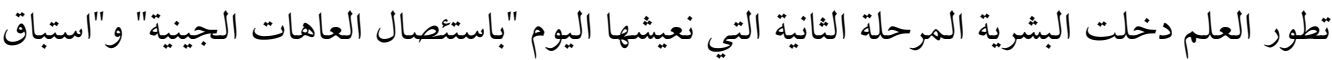

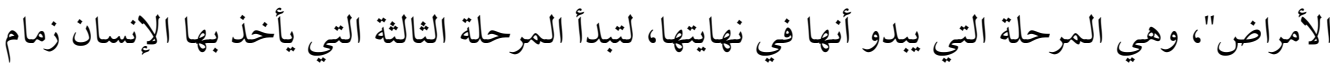

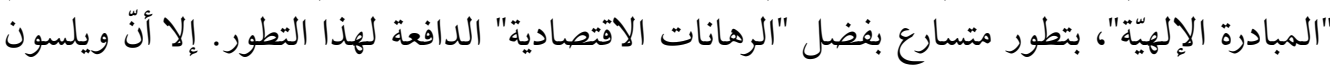

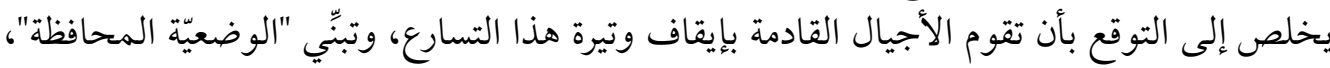

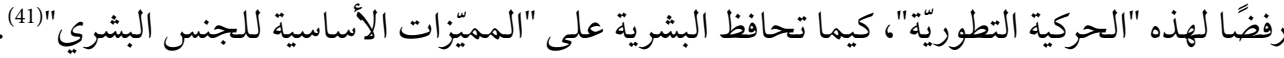

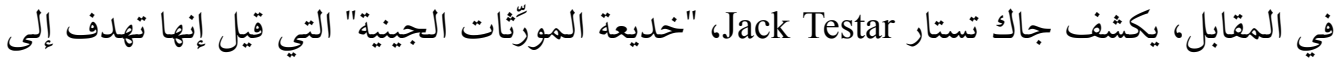
"الزيادة الإنتاجية" للحيوانات والنباتات، من أجل الاستفادة منها حصرًا للنوع الإنساني؛ ما صنع دعوة

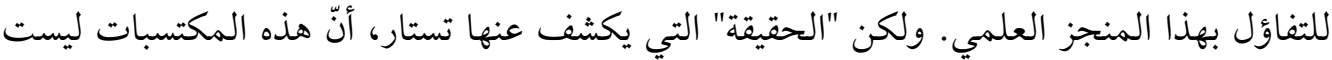

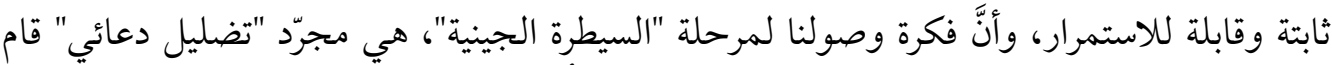

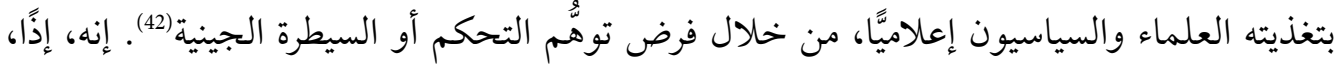

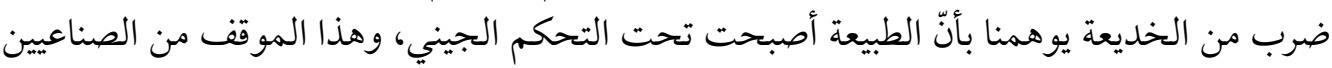

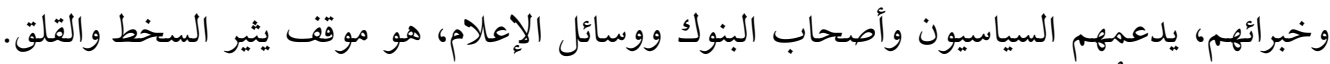

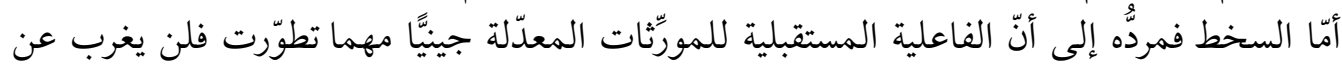
بالنا أنها فُرضت قبل تقديم البرهان، ليس على مخاطرها فحسب، وإنما على إنى فوائدها كذلك. وأمّا القلق فلأن موقف السلطات العلمية والسياسية يوحي بهاجس أيديولوجي يقضي بالإيمان وبفرض

(39) Thomasma, p. 70.

$$
\text { المرجع نفسه، [وآخرون]، ص 384-385. }
$$


الإيمان بالتحكم الجيني، وهو هاجس يقارب التزوير وانعدام المسؤولية. كيف لنا أن نتوقع المستقبل

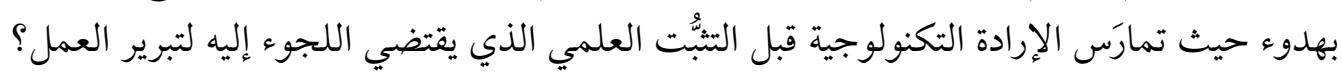

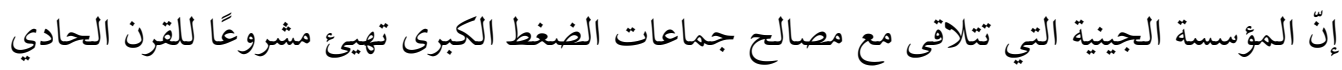
والعشرين، تفرض فيه "التطور بقوّة الأكاذيب والأمر والواقع" (43").

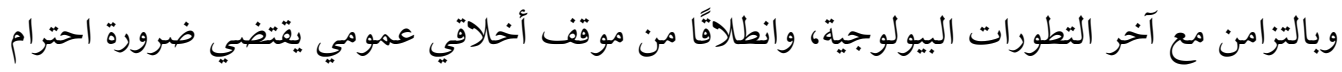

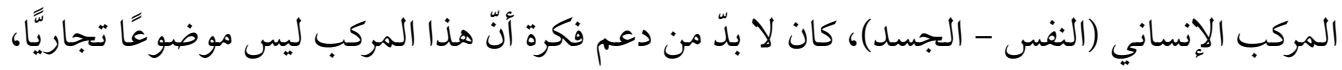

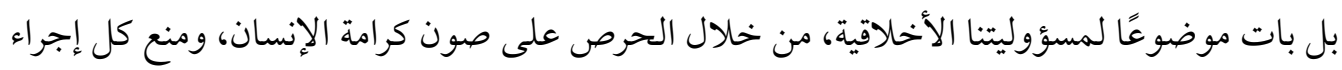

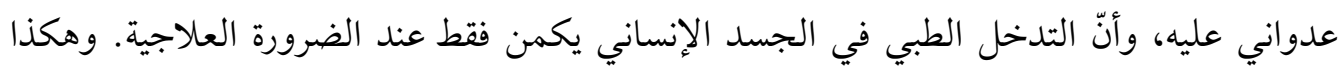

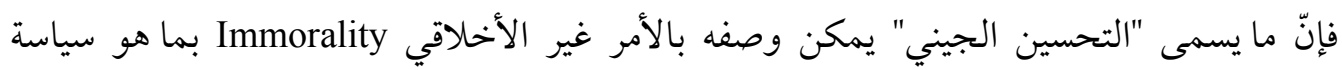

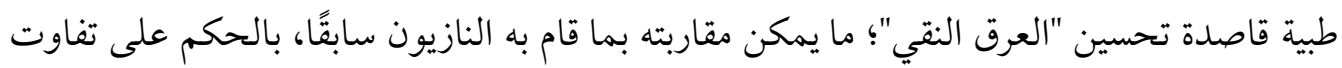

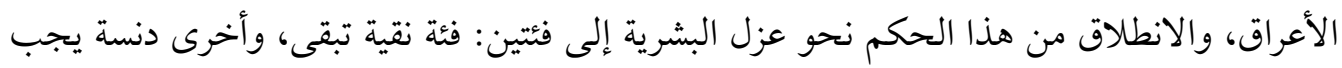

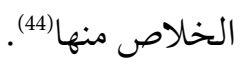

وفي سبيل مزيد من الوقوف على مشكل أخلاقيّات البيولوجيا، من حيث تشابكها مع مفهوم التقدم،

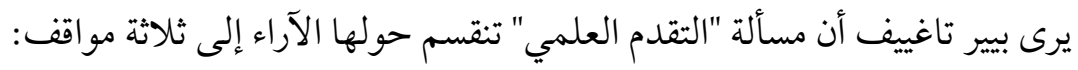

1. تقني محض، يرى أنصاره أن لا سلطة على العلم، ومن ثم لا يعترف هؤلاء بالمشكلات الأخلاقية الناجمة عن التطورات العلمية من الأساس.

2. تقليدي رافض، ومنقسم إلى تيارين: واحد متشدِّد يعود في الأساس إلى تيار الفكر المناهض

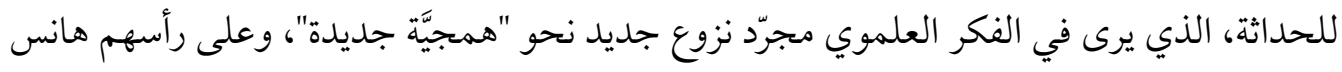

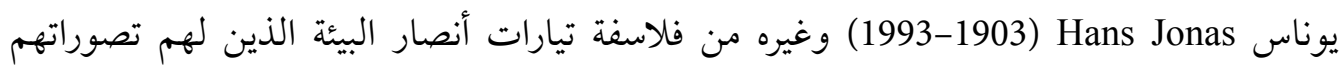

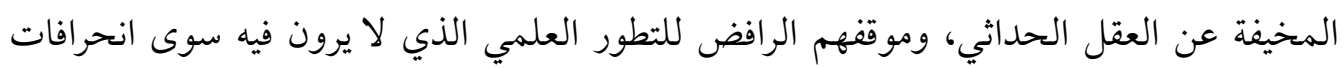

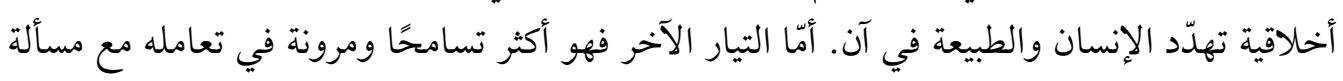

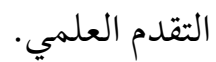

3. يتخذ أنصار الرأي الثالث من مسألة "التقدم العلمي"، موقفًا وسطيًا، باستخدام الحجاج والبراهين

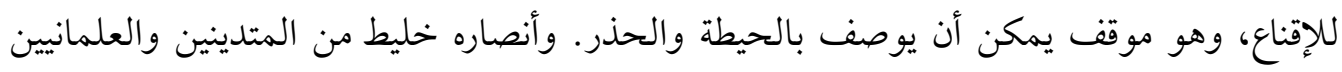

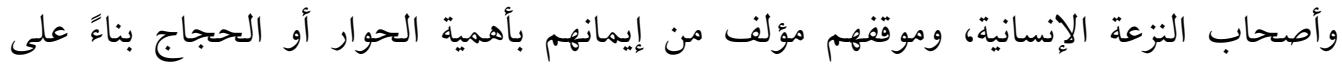

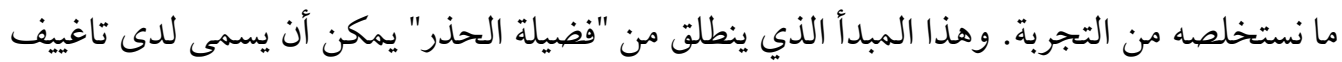


بمبدأ "التشكّك التطوري" (5)، الذي يمكن معه السؤال فلسفيًّا: كيف تحوّل الإنسان إلى ضحية تقدّمه؟ إنه سؤال يحيل مفهوم "التقدم العلمي"، إلى رهن المساءلة النقدية - الأخلاقية.

إنّ تعدّد المواقف الأخلاقية من مسألة التقدم العلمي، يشي بأنّ المشكل الأساس هنا هو مسألة الإيمان

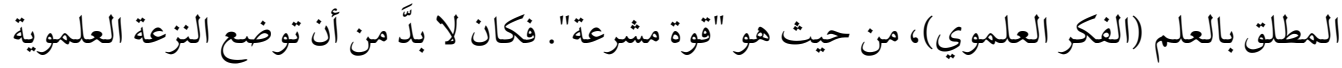

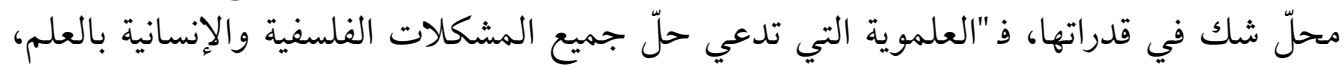

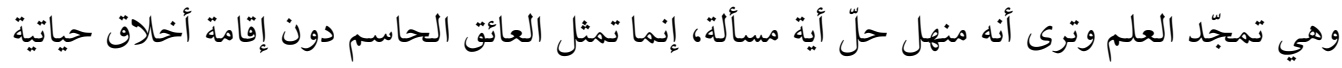

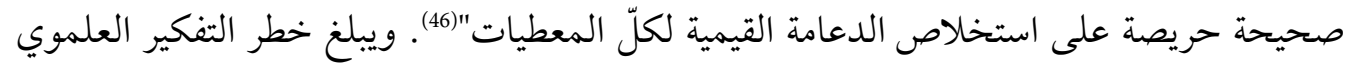

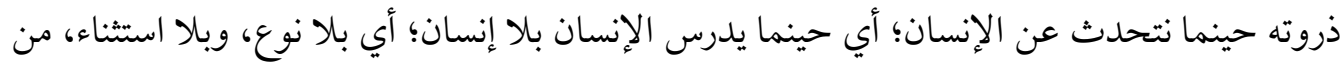

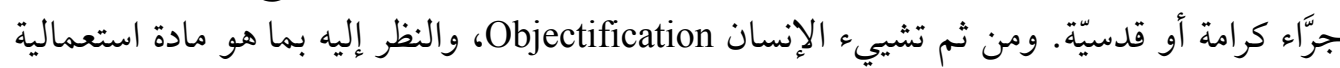

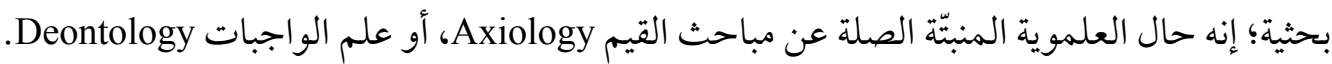

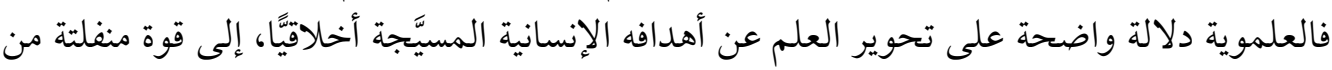

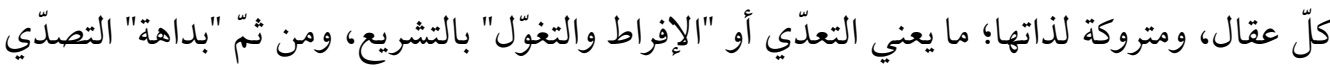

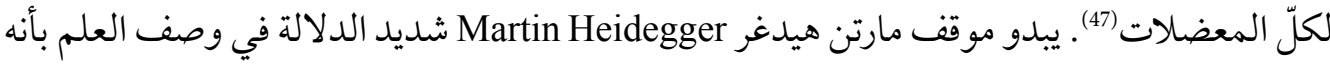

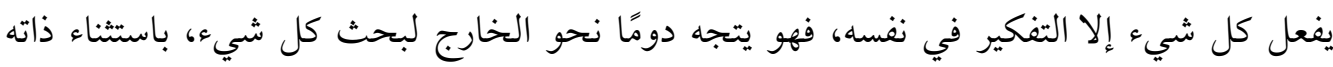

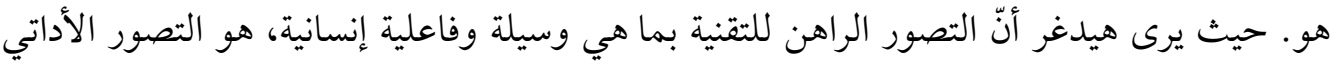

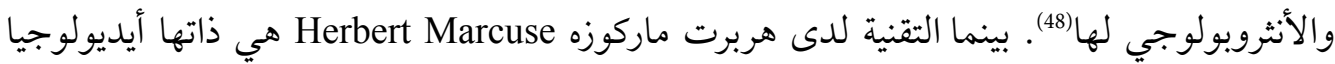
لسيطرة منهجية على الطبيعة وعلى الإنسان (49).

جدير بالذكر أن التقنيات العلمية الحديثة، وماتمثله من مخاطر، خلقت حاجة جدليّة "لمبدأ

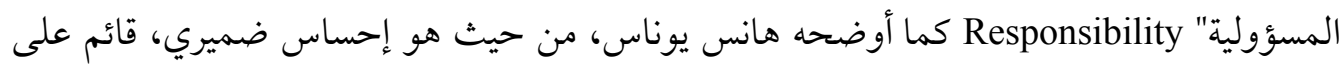

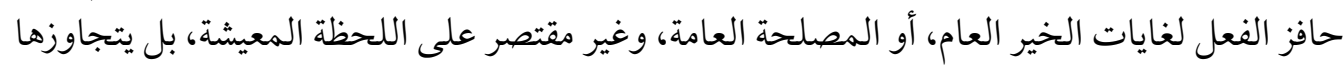

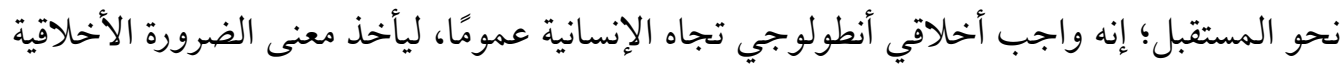

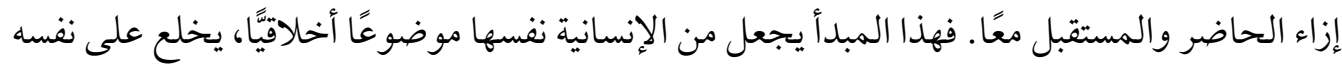

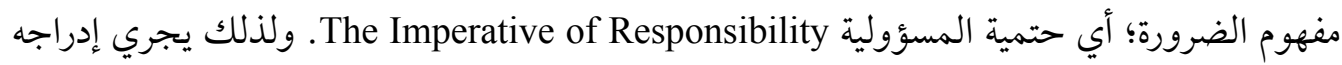

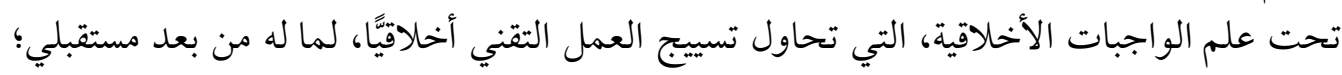

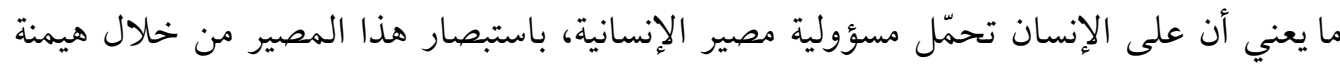

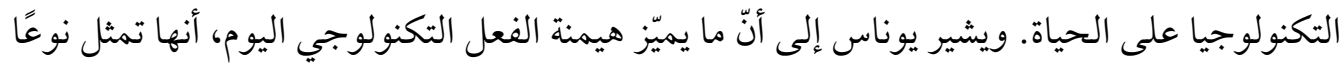

(45) تاغييف، ص 112-113.

روس، ص 119.

المرجع نفسه.

(48) مارتن هيدغر، التقنية - الحقيقة - الوجود، ترجمة محمد سبيلا وعبد الهادي مفتاح (بيروت/ الدار البيضاء: المركز الثقافي

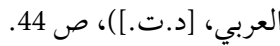
يورغن هابرماس، العلم والتقنية ك "أيديولوجيا"، ترجمة حسن صقر (كولونيا: منشورات الجمل، 2003)، ص 44-45. 
جديدًا من الفعل البشري؛ بسبب حداثة أساليبها، إلى جانب طبيعة بعض أهدافها، والانتشار التراكمي -

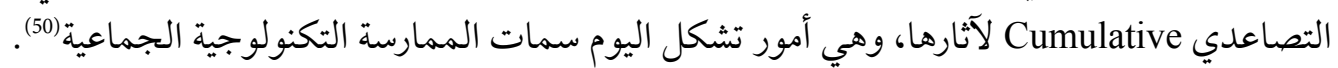
يشدّد يوناس على أنّ المسؤولية هي جملة أخلاق ضرورية تأخذ المستقبل في الحسبان عند دراستها

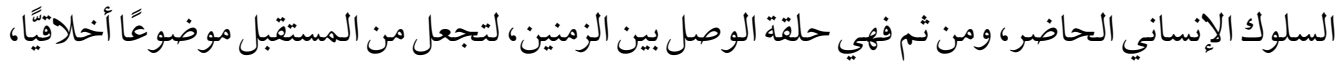

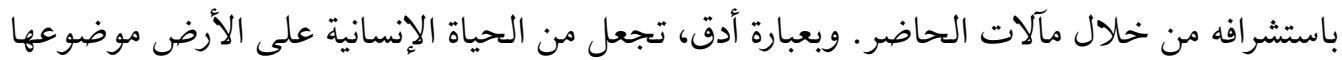

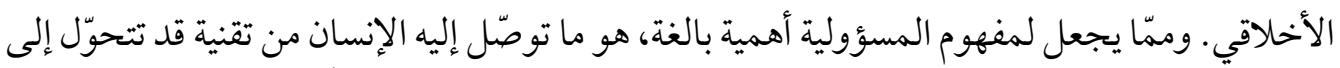

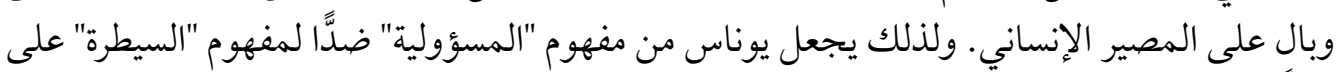

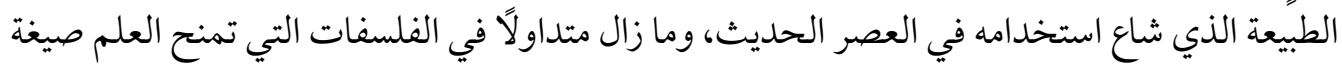

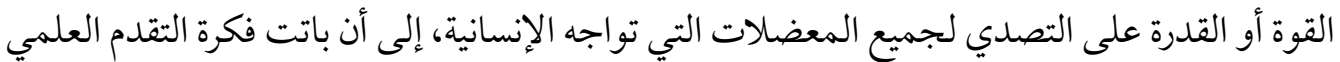

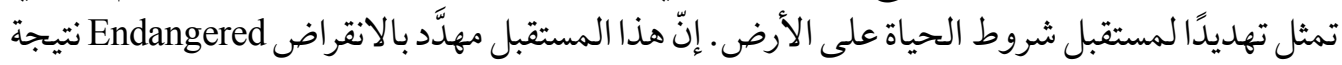

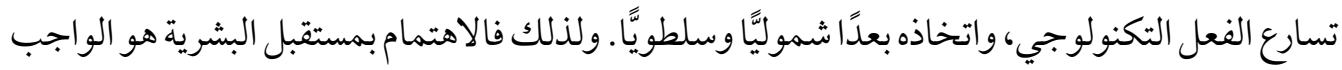

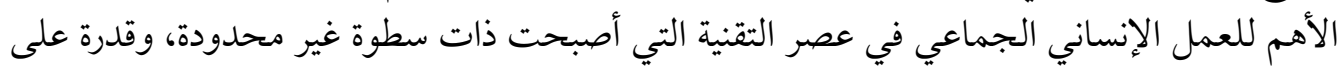

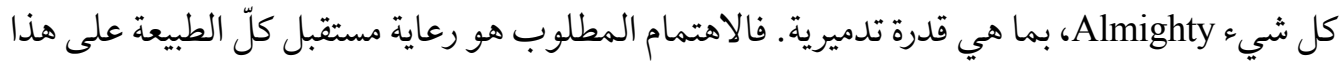

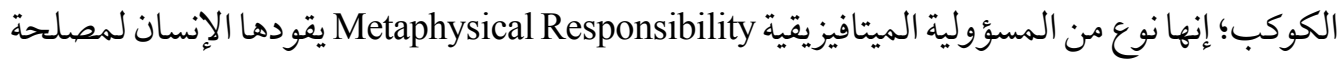

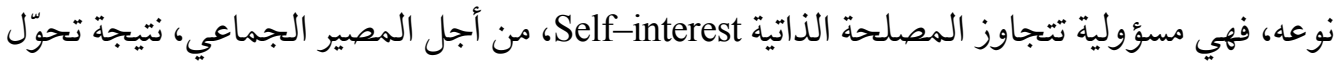

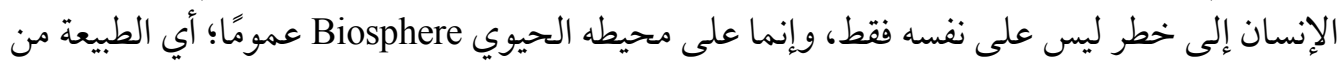

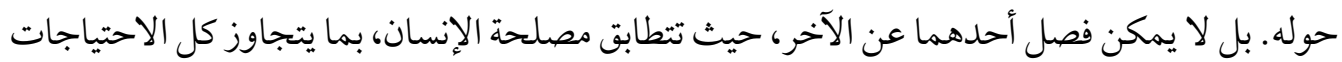

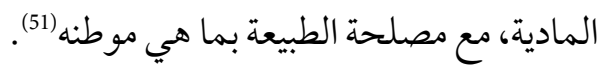

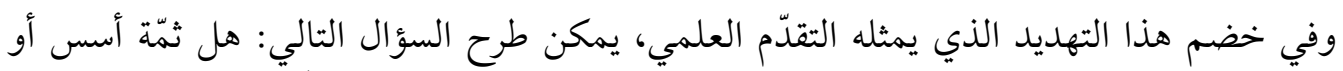

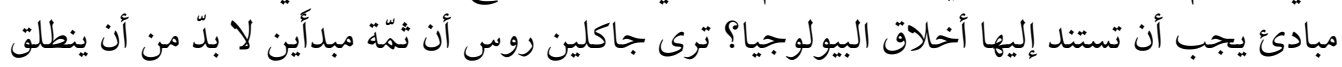

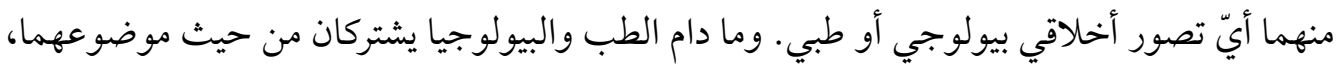

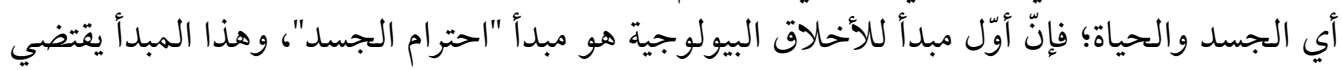

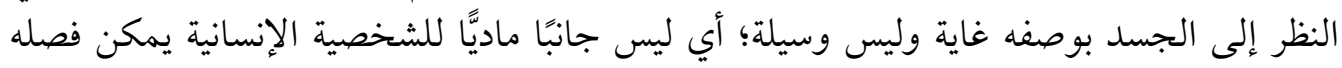

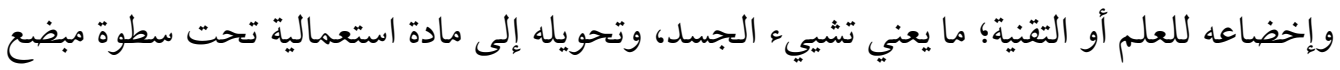

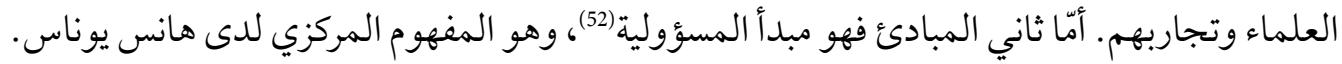

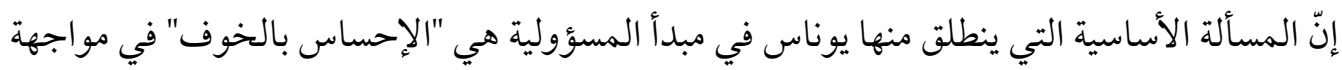

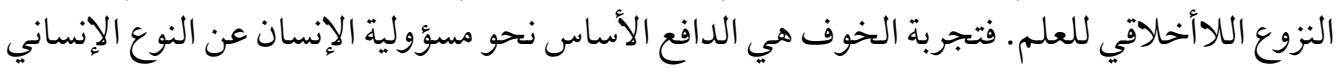

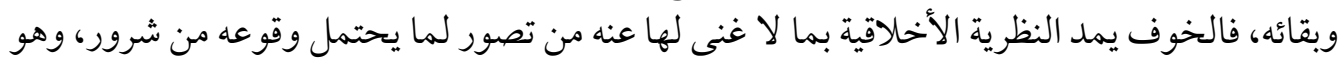

(50) Hans Jonas, The Imperative of Responsibility, Hans Jonas \& David Herr (trans.) (Chicago: The University of Chicago Press, 1984), pp. 22-24.

(51) Ibid., pp. 136-137. 
بذلك يصبح "أول ضرورة مبدئية لازمة لإقامة نظرية أخلاقية قوامها المسؤولية التاريخية"(53). فهذا الخوف هو واجب تحوُّطي - احترازي Prudential لأجل تفادي تلك التصورات المرعبة التي يرسمها المخيال العلمي للمستقبل الإنساني. فتجربة الخوف تعني ضرورة تشييد أخلاقيّات الحفظ والحماية

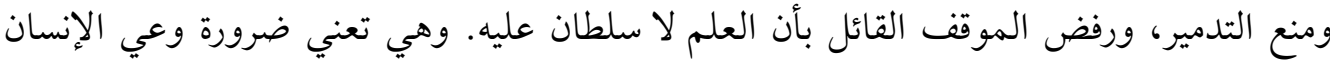
بالخطر الكبير الماكث في القدرة العلمية التقنية، بما هي قدرة مآلاتها التدمير والهيمنة في آني آن معًا. إنّا لإني منح العلم الحرية المطلقة، وفكّ الارتباط بينه وبين الأخلاق لا يعنيان سوى التعجل بالدئ فالدمار الذاتي الذي سيحدثه الإنسان بنوعه الإنساني وبالطبيعة من حوله، "وفي الحالة المنذرة بالدمار التي تعيشها البشرية اليوم، حيث تتهددها كارثة كونية لا مناص منها فيما لو تركنا الأمور [...] تجري على الإسي العواهن.

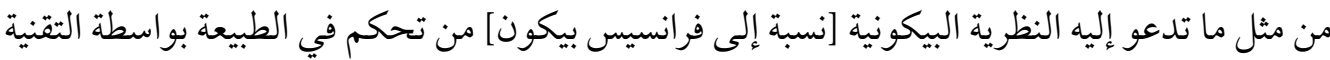

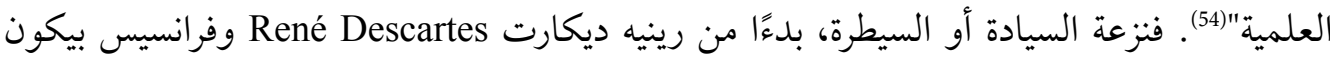

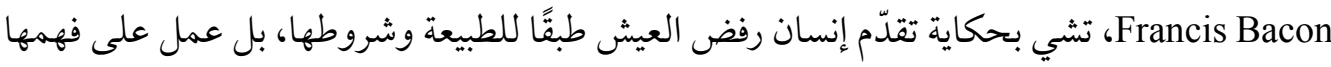
وتذليلها لصالحه باعتباره سيّرًا لها (55).

يحاول رويشي إيدا فهم المشكل الأخلافي "للتحسين الجيني" بإقحام مفهوم "المساواة في الكرامة"

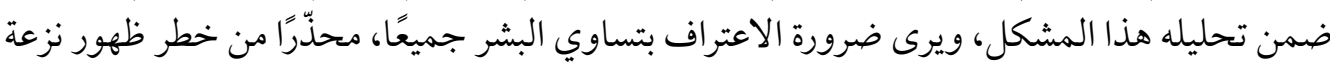

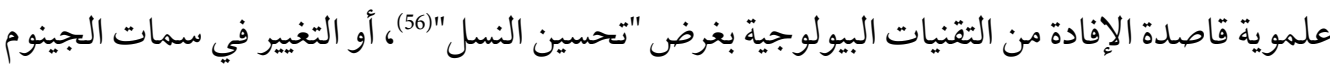

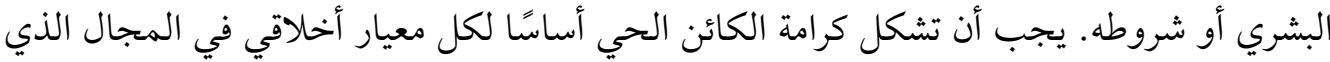

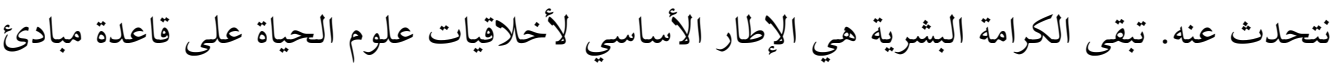

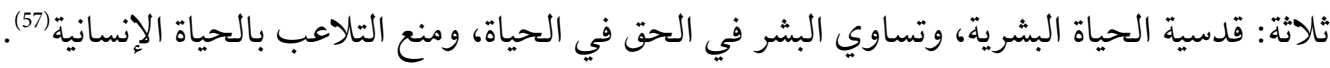

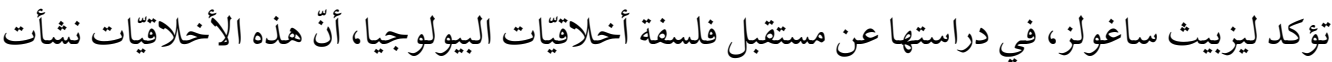
بالأساس في سياق المحافظة على حقوق الإنسان، لتأتي المساواة على رأس قائمة هذه الحقوق. "لا شيء له حياة يجب أن يموت" بهذا المعنى تؤكد ساغولز الحق في الحياة بوصفه قيمة يتساوى بها

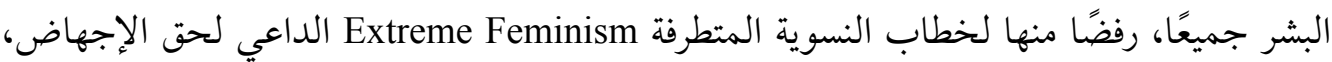
والقول بضرورة تأكيد الحق في الحياة، بما في ذلك حياة الأجنة، والمساواة الكونية في هذا الحق (58).

يؤيد جورج أنّاس George Annas (1825-1894) فكرة المساواة الجوهرية بين البشر، ويعقد

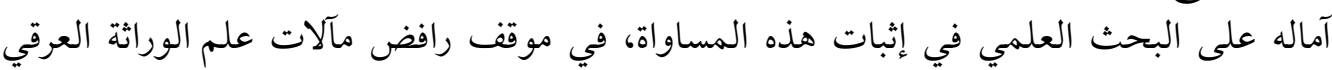
Phylogenetics

$$
\begin{aligned}
& \text { (53) تاغيف، ص } 114 . \\
& \text { المرجع نفسه. }
\end{aligned}
$$

(55) Charles Rubin, "Human Dignity and the Future of Man," in: Schulman et al., p. 157.

$$
\text { بيندي [وآخرون]، ص 356-357. }
$$

(58) Lisbeth Sagols, "The Bio-philia Future of Bioethics," in: Callahan et al., pp. 23-26. 
حاملة لخصائص تحدّد إمكانيات الأفراد وتصرفاتهم وتفرّق بينها (59)، وهي الفكرة التي لا يدعمها أي

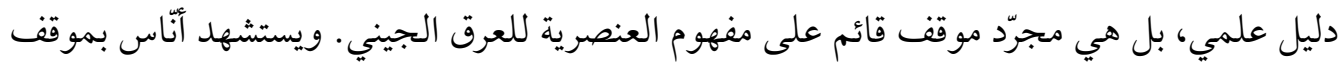

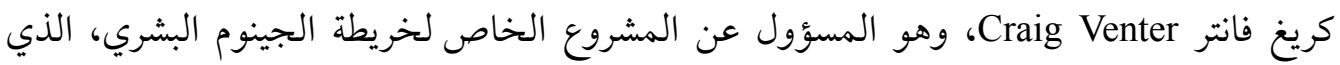

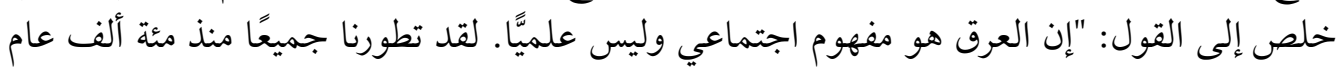

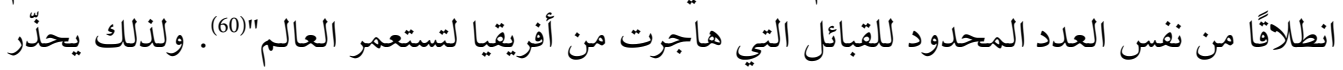

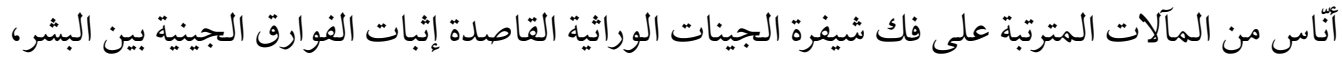

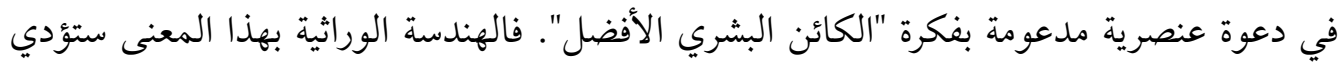

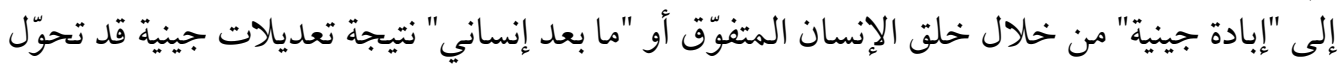

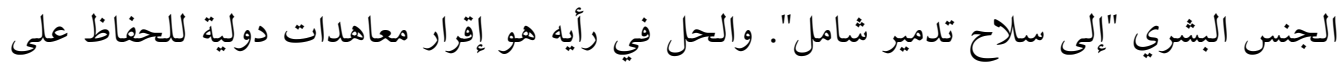

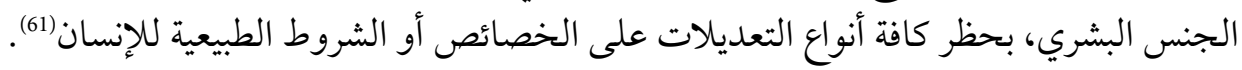

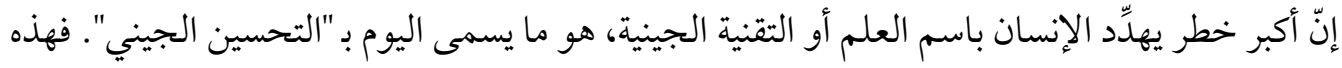

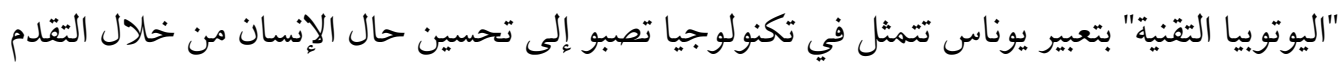

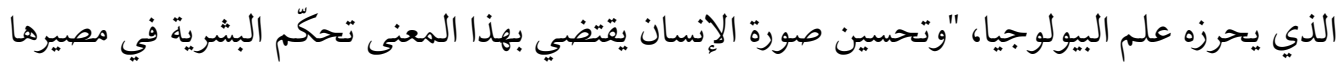

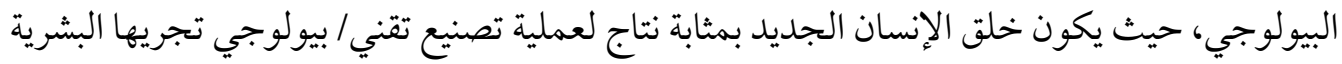

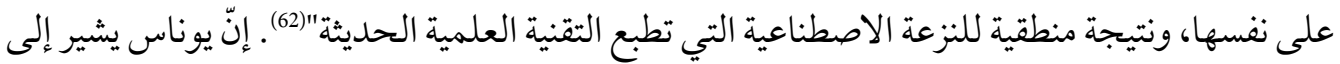

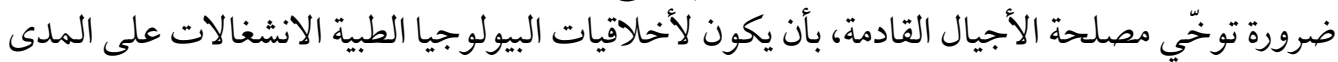

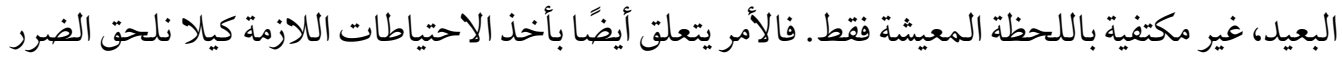

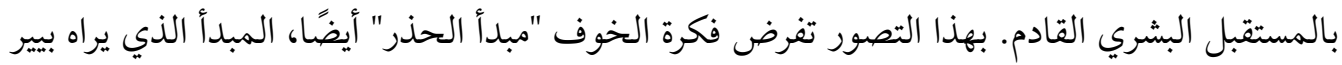

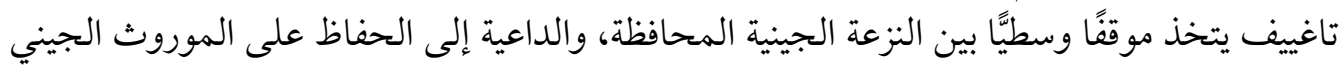

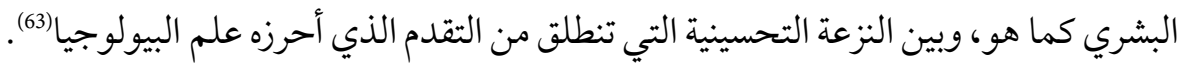

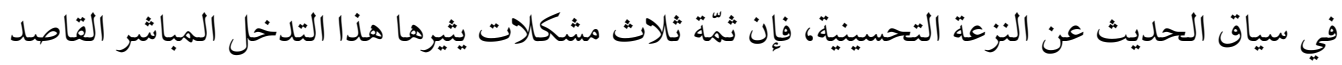

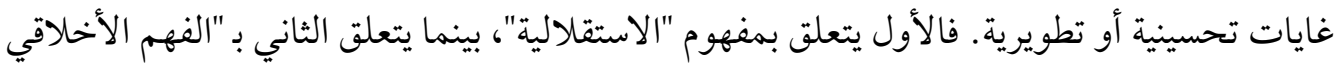

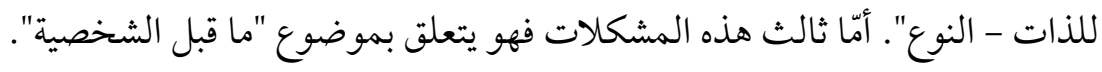

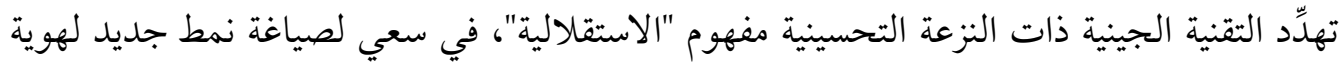

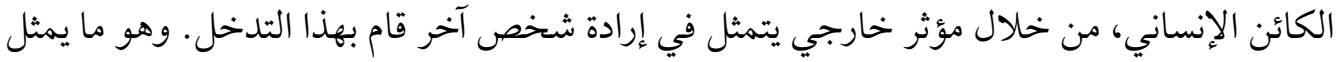

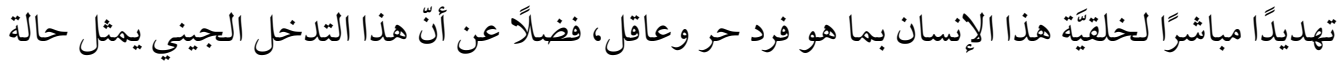

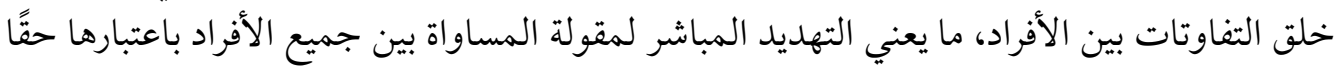

$$
\begin{aligned}
& \text { (59) بيندي [وآخرون]، ص } 423 . \\
& \text { (60) المرجع نفسه، ص } 424 \text { (60) }
\end{aligned}
$$

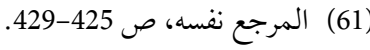

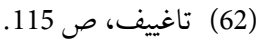

$$
\begin{aligned}
& \text { (63) المرجع نفسه. }
\end{aligned}
$$




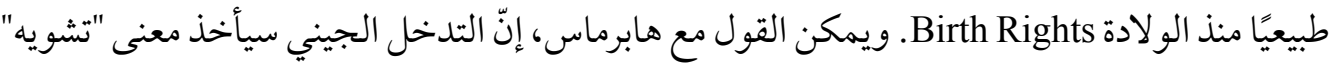

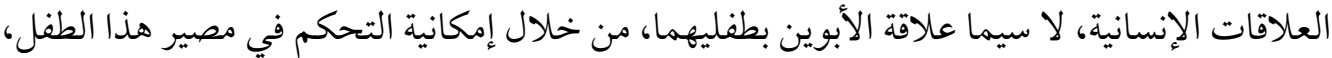

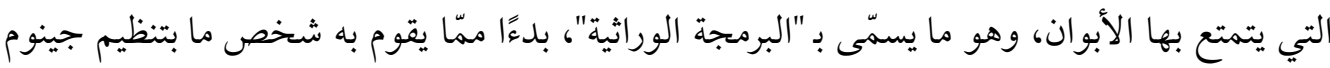

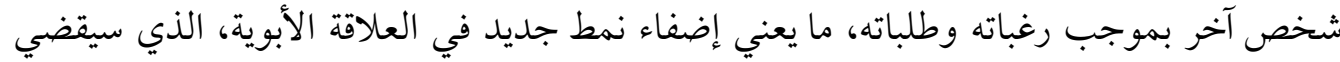
على حق الاستقلالية لهذا الطفل (64).

أمّا ثاني مشكلات النزعة التحسينية، فهو "الفهم الأخلاقي للذات - النوع"، حيث يقوم الفهم الأخلاقي

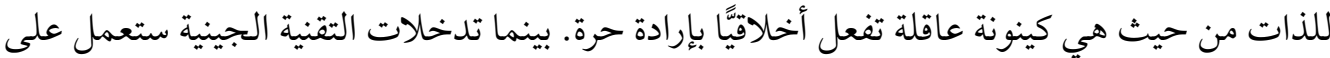

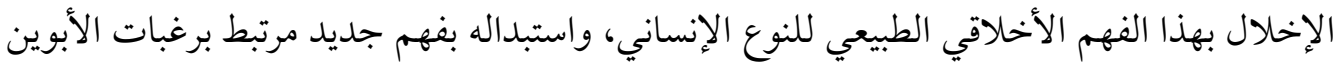

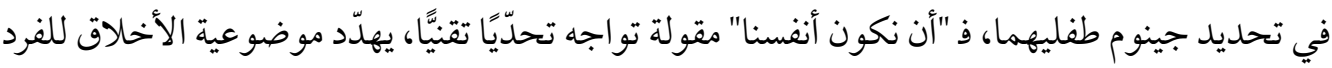

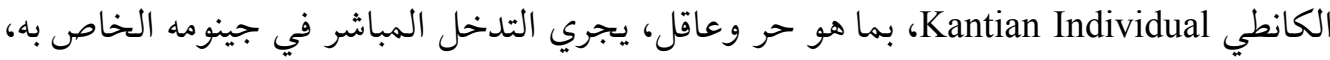

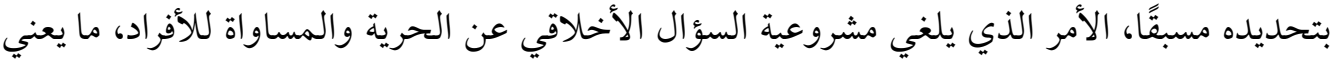

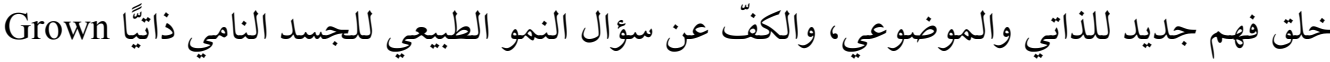
Body

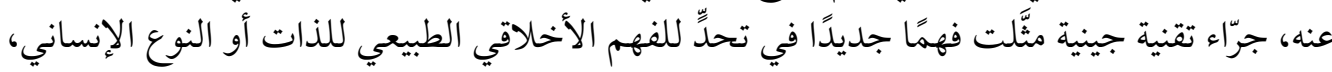

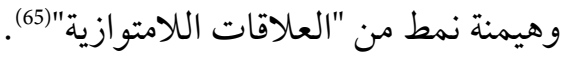

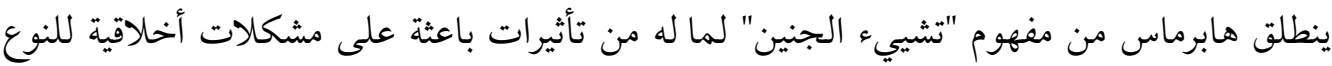

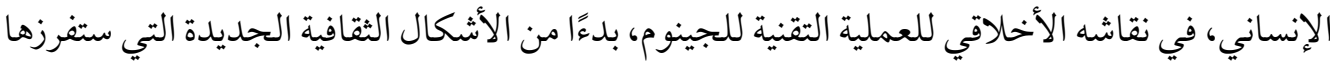

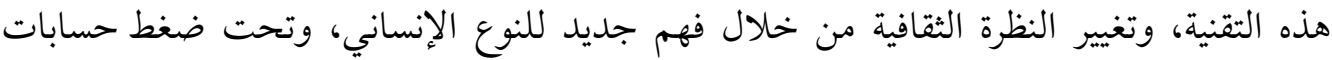

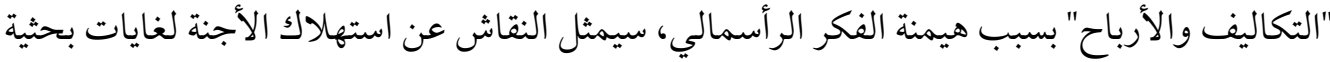

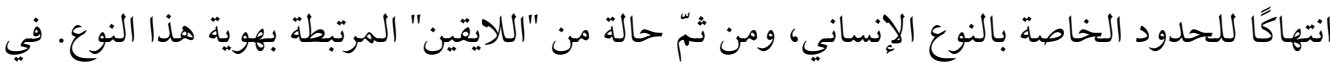

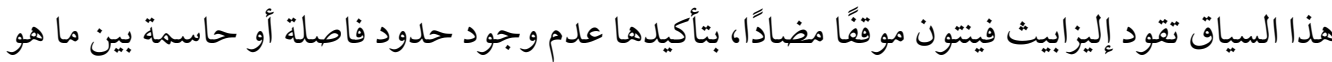

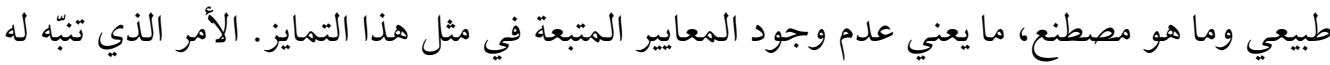

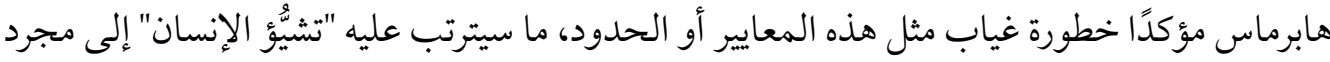

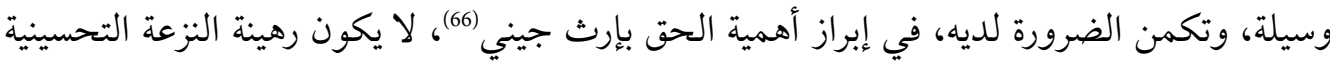

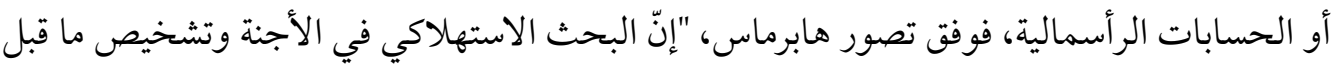

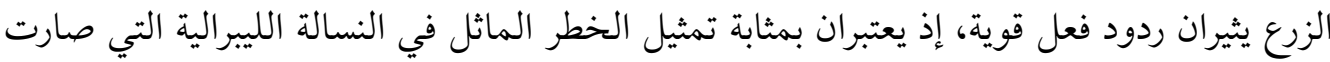
على أبوابنا" (67).

(64) معتز الخطيب، "الحدود الأخلاقية للتدخل الجيني: النقاش الفلسفي والفقهي حول أخلاقيات التقنية الوراثية"، تبيّن، مج 7،

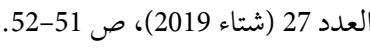

$$
\begin{aligned}
& \text { 6 المرجع نفسه، ص 52-53. } \\
& \text { المرجع نفسه، ص 53-54. } \\
& \text { هابرماس، مستقبل الطبيعة، ص } 33 .
\end{aligned}
$$




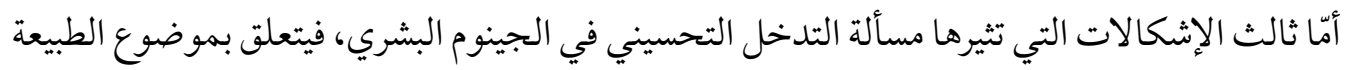

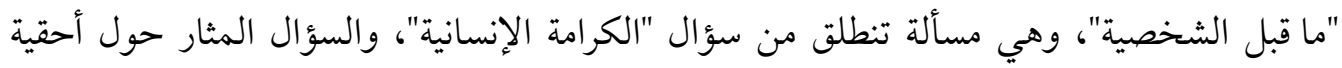

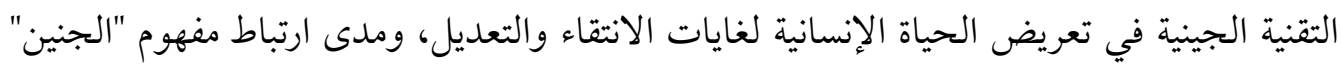

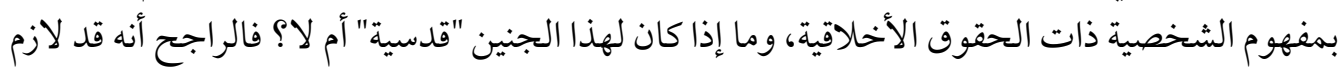

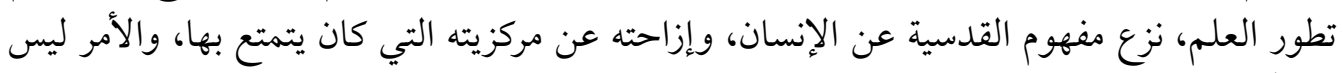

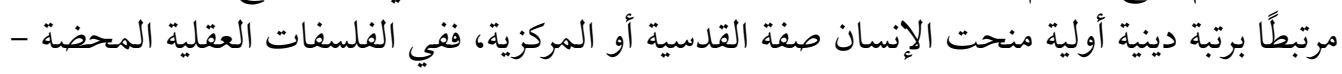

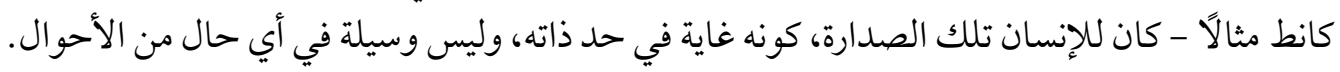

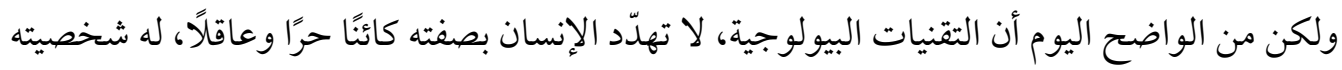

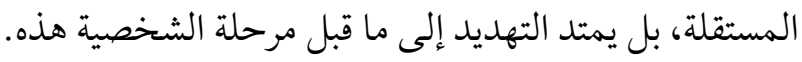

يبقى سؤال "القدسية" مرتبطًا بسؤال "الحياة" نفسها، الأمر الذي جعل مشكل التقنية الجينية أشد تعقيدًا،

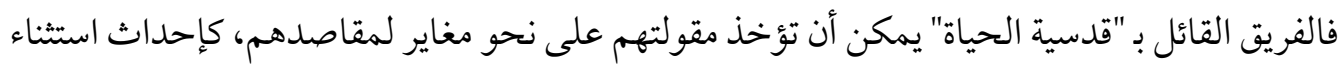

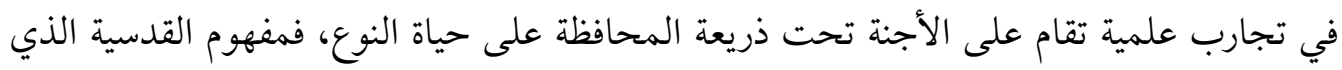

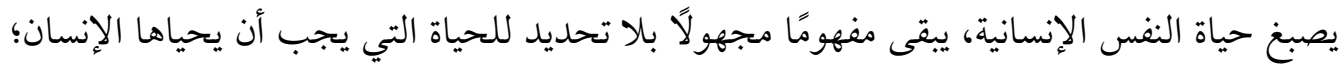

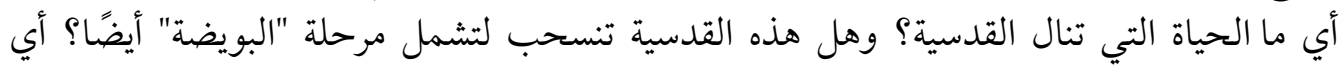

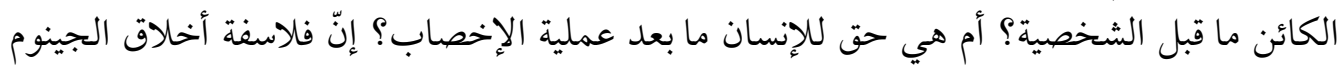

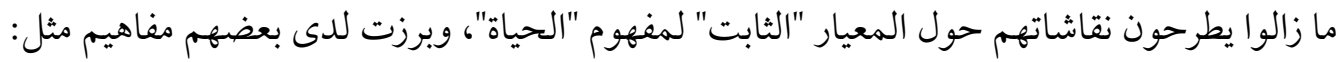

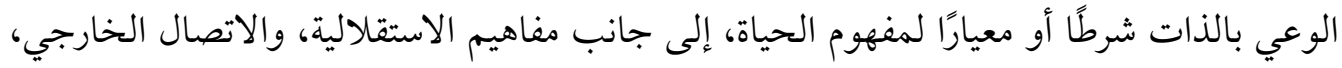

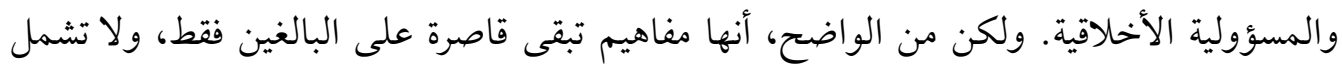

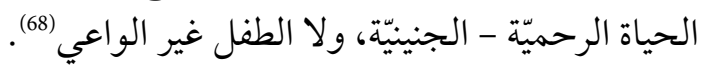

حاولت الفيلسوفة الكاثوليكية تيريزا إغليسياس Teresa Iglesias حلّ "مشكل الشخصية" بالتركيز على

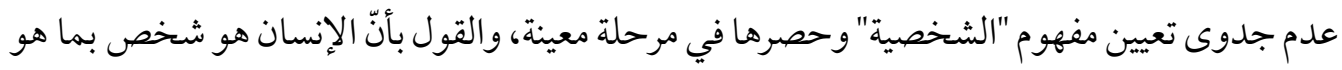

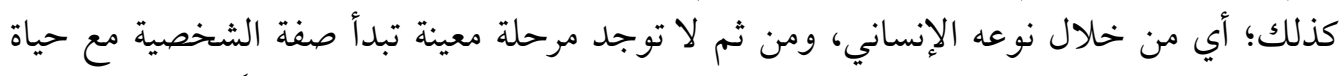

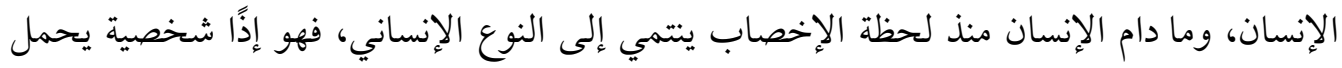

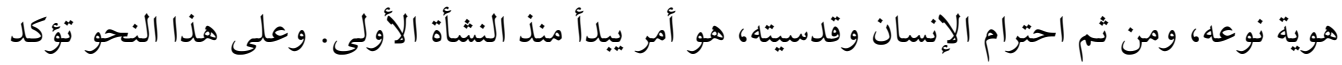

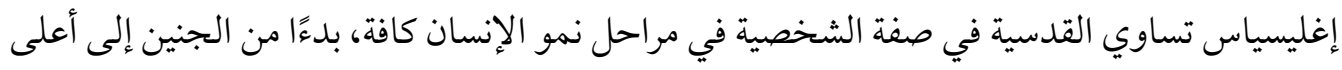

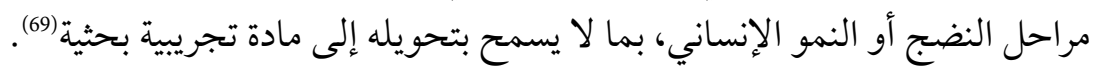
تتخذ أنجا كارنين Anja Karnein موقفًا مقاربًا لموقف إغليسياس، ولكنها تختلف في تعبيرها بالقول

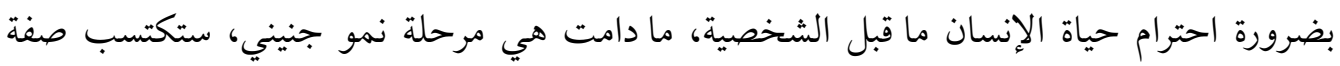

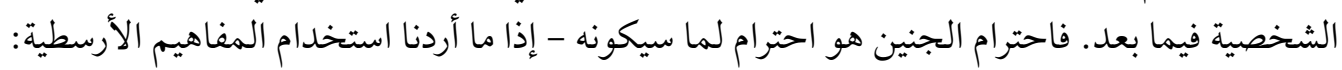




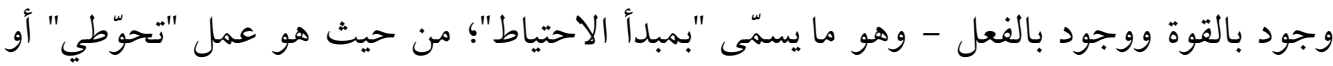

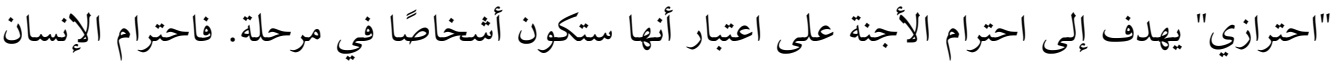

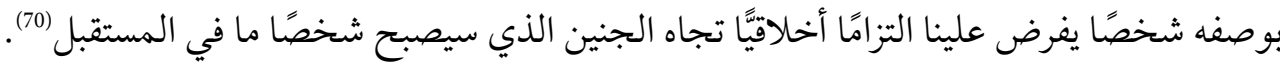
إنّ الخوف خاصية إنسانية حيال المستقبل المجهول في خضم تطورات بيولوجية تحايثها النزعة العلمويّة،

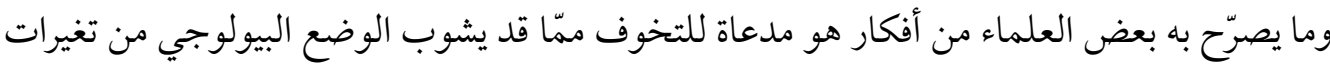

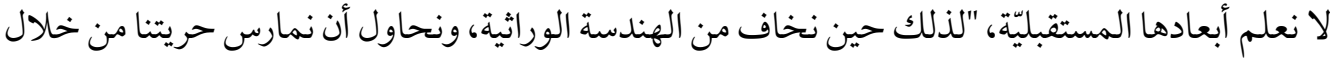

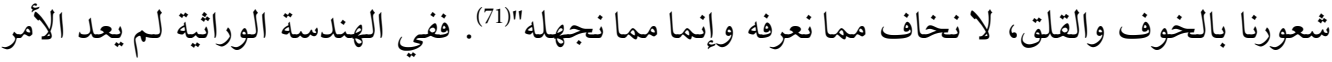

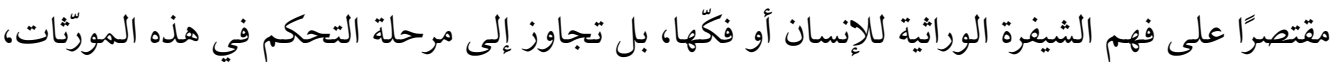

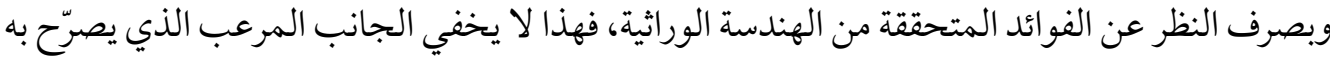

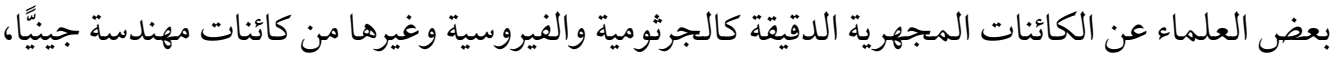

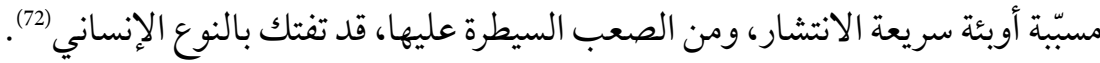

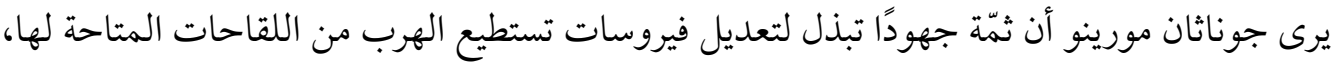

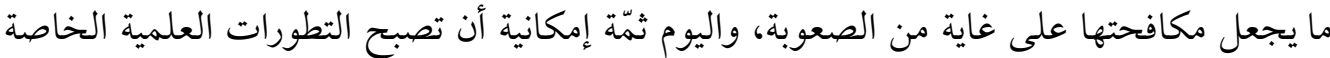

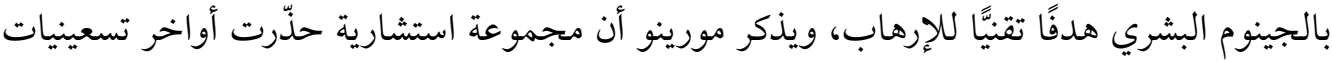

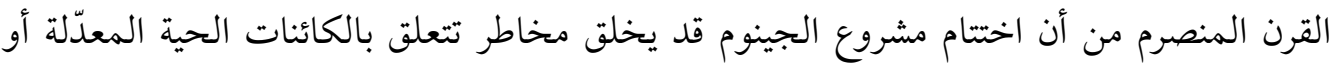

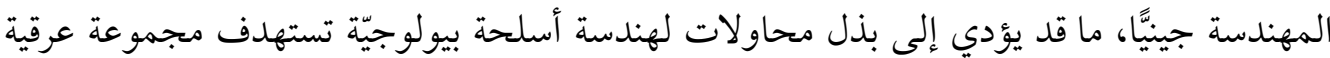
معينة (73).

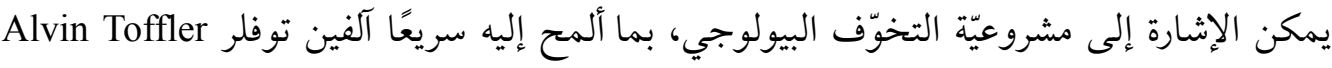

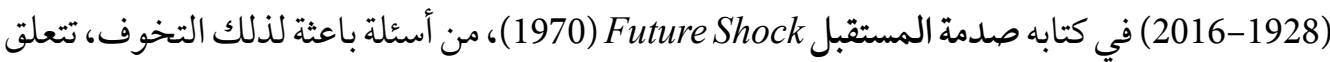

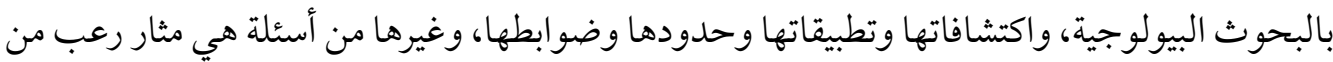

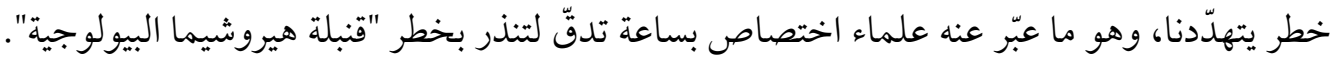

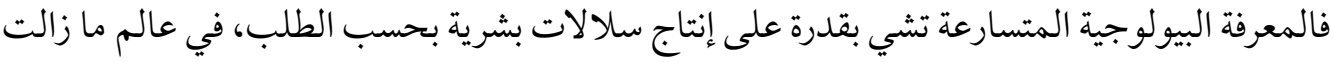

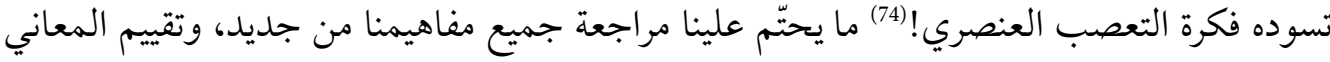

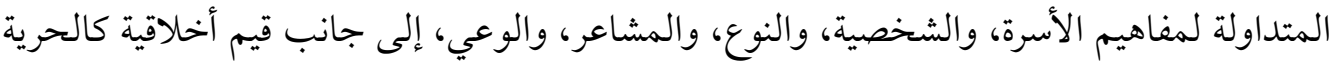

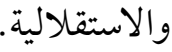

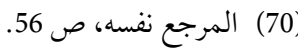

$$
\text { البقصمي، ص } 202 .
$$

المرجع نفسه، ص 203-204.

(73) Jonathan Moreno \& Bonnie Steinbock (eds.), "Bioethics and Bioterrorism," in: Bonnie Steinbock (ed.), The Oxford Handbook of Bioethics (Oxford: Oxford University Press, 2007), p. 732.

(74) عبد الحسن صالح، التبؤ العلمي ومستقبل الإنسان، سلسلة عالم المعرفة 48 (الكويت: المجلس الوطني للثقافة والفنون

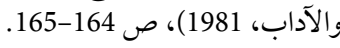




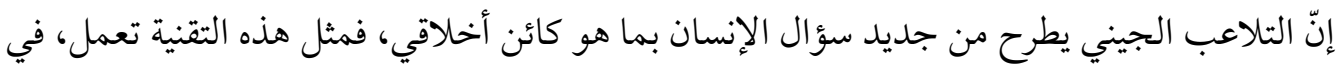

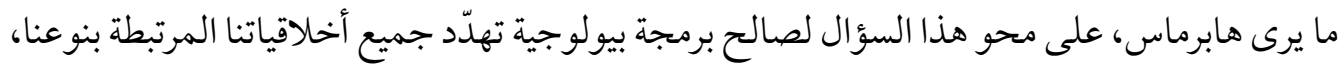

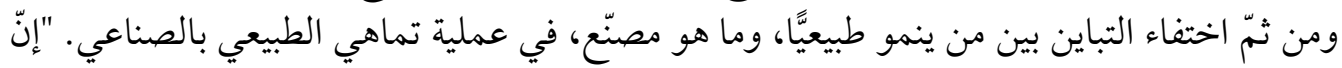

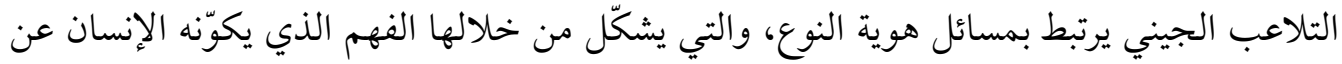

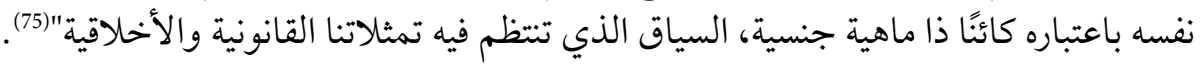

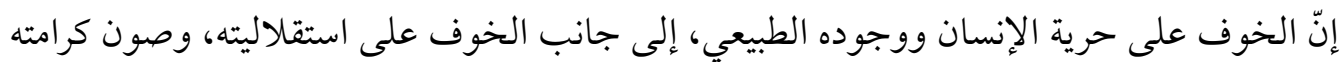

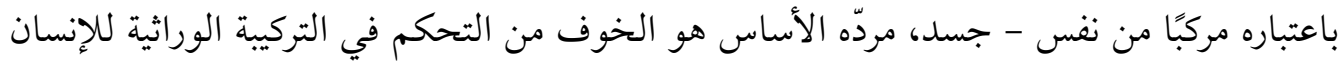

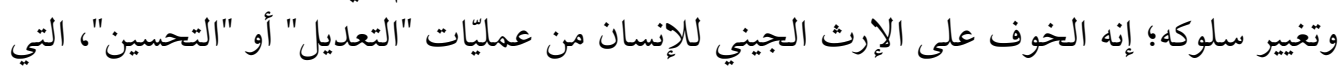

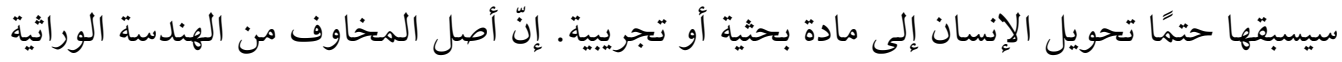

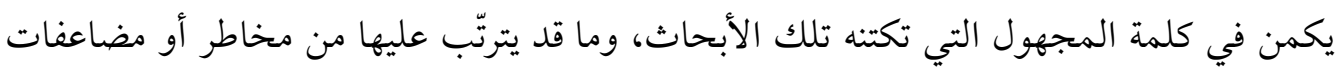

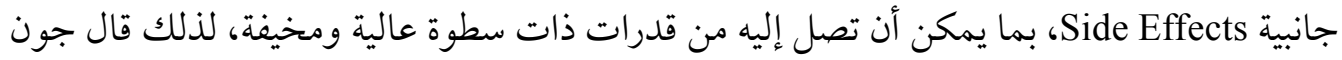

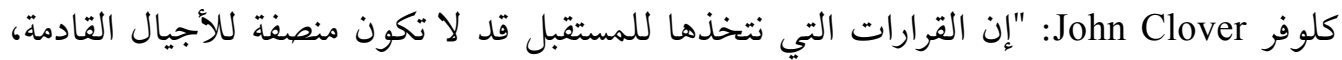

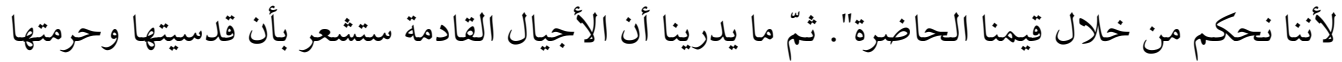

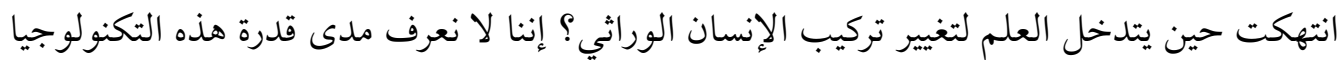
على التغيير (76).

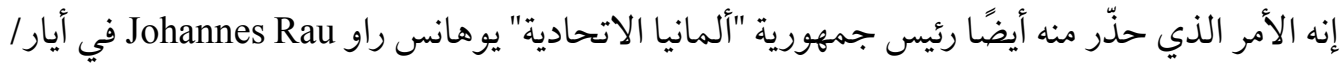

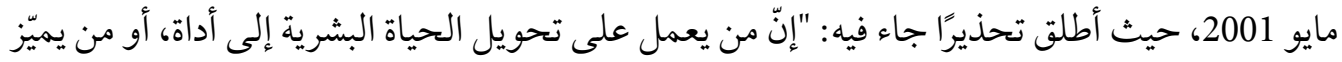

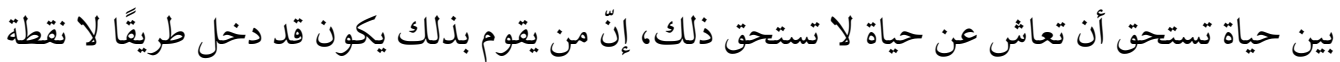

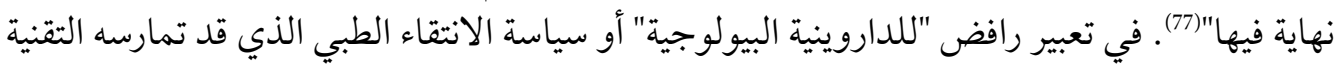

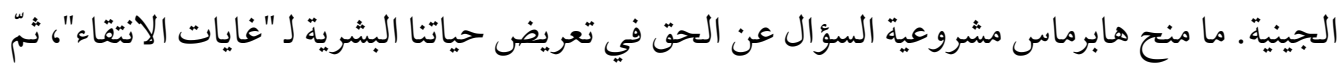
عمَّا يمكن فعله في مجابهة "لوبي التكنولوجيا الوراثية" (78).

وفي مفهوم شديد الدلالة، أبان مشروعية التخوف البيولوجي، درج مؤخرًا استخدام مفهوم "الإرهاب

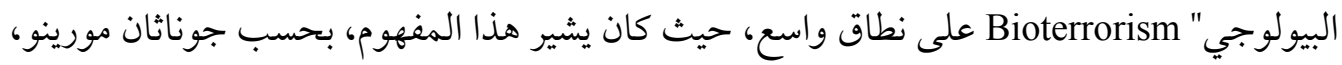

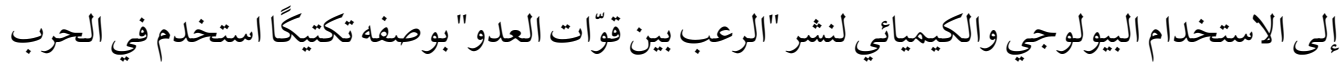

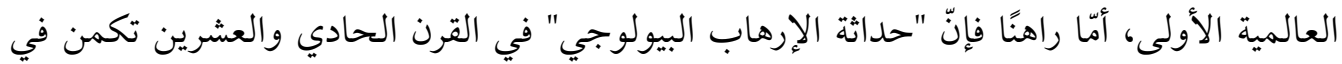

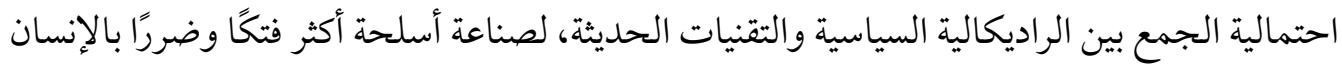

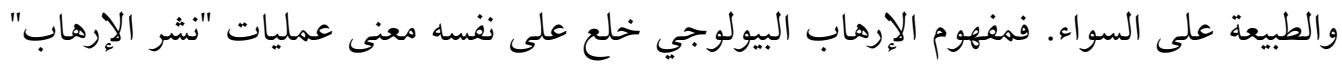

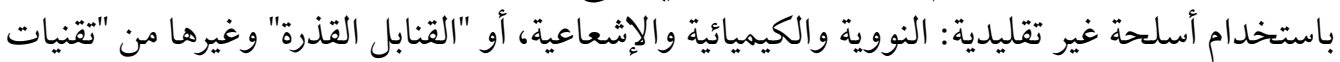

$$
\begin{aligned}
& \text { (75) هابرماس، مستقبل الطبيعة، ص } 32 \text { (76) } \\
& \text { البقصمي، ص } 207 . \\
& \text { هابرماس، مستقبل الطبيعة، ص } 28 . \\
& \text { المرجع نفسه، ص } 29 .
\end{aligned}
$$


إرهابية"، في عملية انزياح ما هو تقني نحو السيطرة المدفوعة بإرادة القوة بالمعنى الاستراتيجي، ممّا خلق مشكلات أخلاقية جمّة مرتبطة بهذه التهديدات للحياة الإنسانية (79).

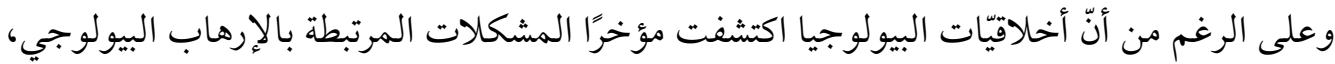

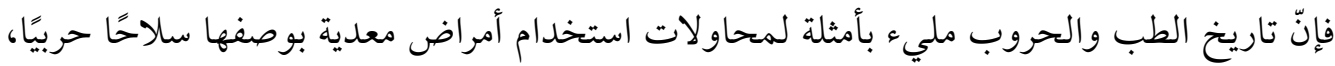

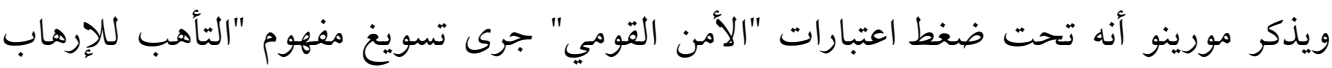

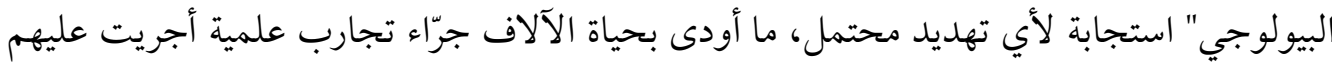

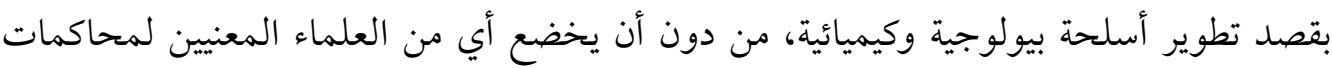

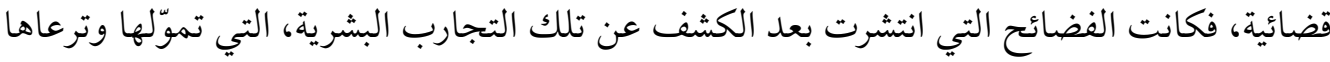

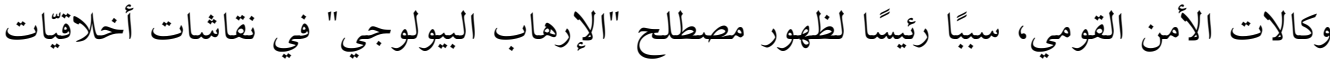

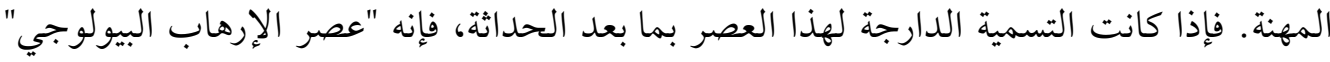

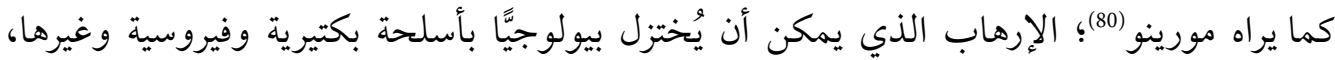

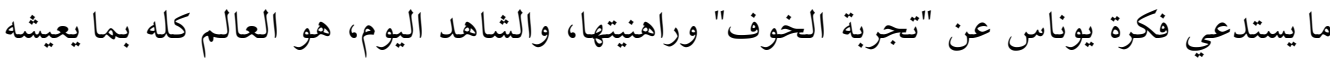
من خوف انتشار فيروس كورونا المستجد (كوفيد-19)، ما يعزّز مشروعية السؤال عن كيفية تحوّل

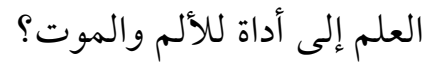

\section{حَاتمة}

إنّ أخلاقيّات البيولوجيا رغم مطارحاتها التأسيسية، وتعدّد مؤثراتها، كانت تعني في المقام الأول الجسر

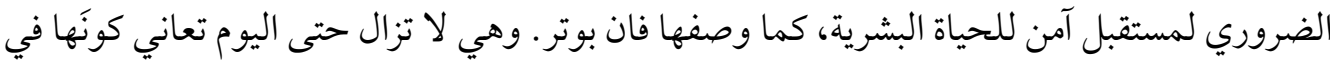

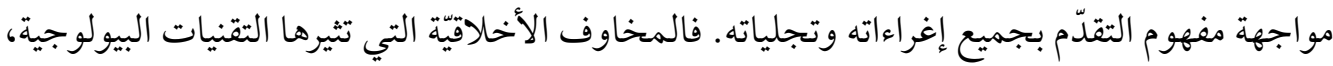

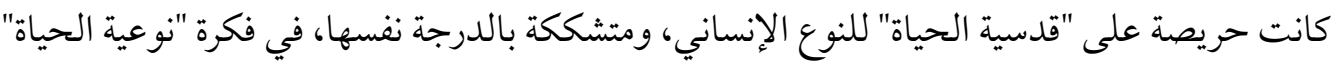

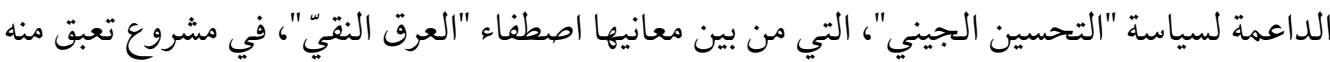

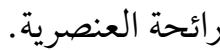

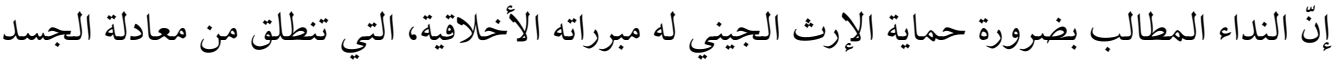

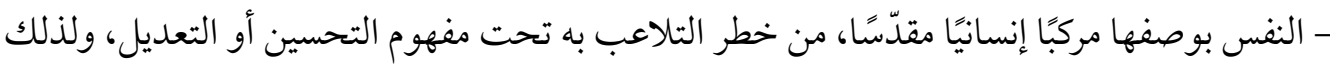

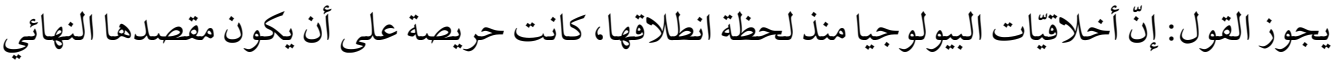

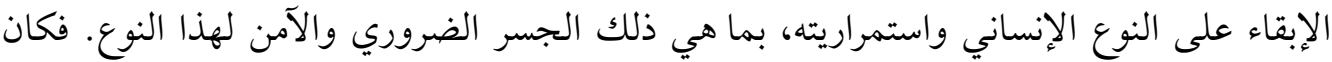

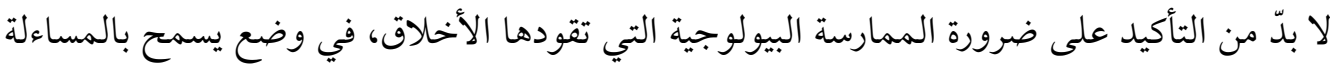

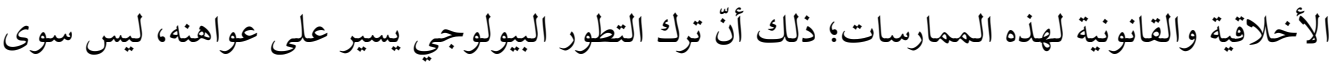
التعجل بالدمار الجيني للإنسان، والدمار البيئي للطبيعة.

(79) Moreno \& Steinbock, pp. 721-722.

(80) Ibid., pp. 722-724. 
يمكن في خاتمة هذه الدراسة إعادة التساؤل فلسفيًّا: ما الموقف الأخلاقي الملائم الذي يمكن تبنّيه

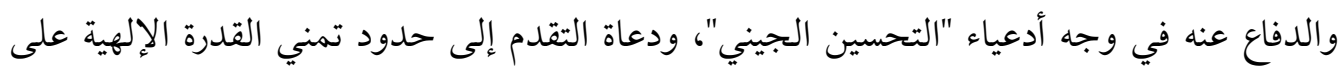

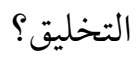

حاولت الدراسة إثبات لاأخلاقية "التحسين الجيني"، وعدم مسؤوليته، وأحقيّة التخوف من المجهول

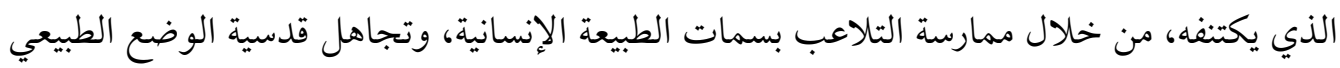

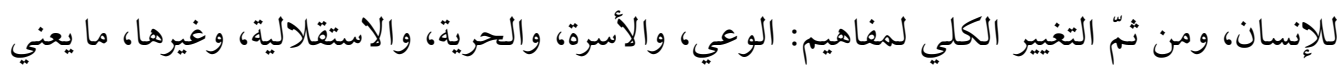

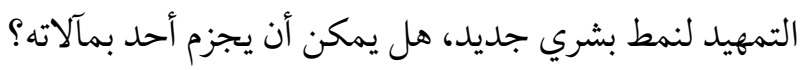

خلاصة القول إنّ استشكال الخوف الذي طرحه يوناس، هو تأكيد مسؤولية الإنسان عن نوعه. فالخوف

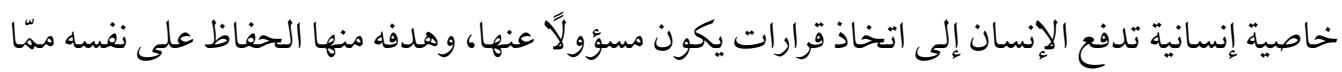

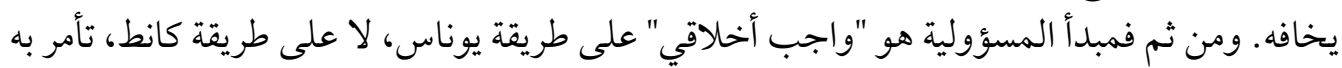
الحكمة والحذر، لا القانون الأخلاقي القبلي.

\section{References}

المـراجع

العربية

أراس، جون. "النظرية والبيو إتيقا". ترجمة شيماء عطية وأحمد فاروق. دفاتر فلسفية (2015). البقصمي، ناهدة. الهندسة الوراثية والأخلاق. سلسلة عالم المعرفة 174. الكويت: المجلس الوطني للثقافة والفنون والآداب، البعادئ 1993.

بوفتاس، عمر . "البيو إتيقا: نحو فكر أخلاقي جديد". دفاتر فلسفية. العدد 9 (2015).

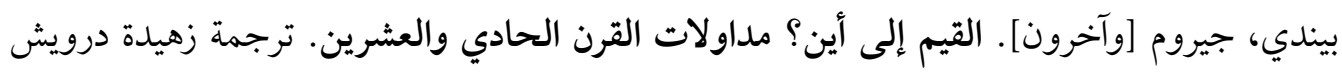

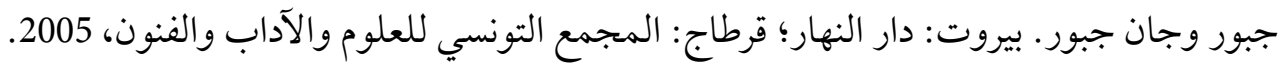
تاغييف، أندريه بيير. "أخلاقيات البيولوجيا: نحو مشروع قضية فكرية". ترجمة عبد الهادي الإدريسي. مجلة دفاتر الشمال. العدد 7 (2003).

الخطيب، معتز. "الحدود الأخلاقية للتدخل الجيني: النقاش الفلسفي والفقهي حول أخلاقيات التقنية

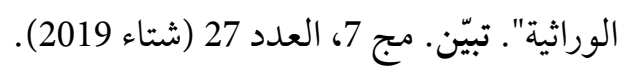

روس، جاكلين. الفكر الأخلاقي المعاصر. ترجمة عادل العوا. بيروت: عويدات للنشر والطباعة، 2001

صالح، عبد الحسن. التبؤ العلمي ومستقبل الإنسان. سلسلة عالم المعرفة 48. الكويت: المجلس والس الوطني للثقافة والفنون والآداب، العند العي ومن 1981. 
هابرماس، يورغن. العلم والتقنية ك "أيديولوجيا". ترجمة حسن صقر. كولونيا: منشورات الجمل،

مستقبل الطبيعة الإنسانية: نحو نسالة ليبرالية. ترجمة جورج كتوره. بيروت: المكتبة

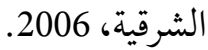

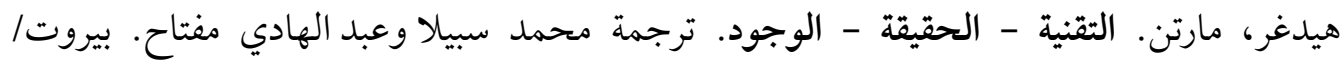

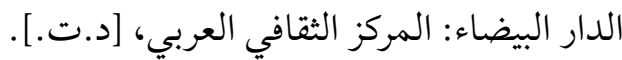

الأجنبية

Callahan, Daniel et al. Global Bioethics: What for? Paris: The United Nations Educational, 2015.

Hottois, Gilbert. Evaluer la technique: Aspects éthiques de la philosophie de la technique. Paris: Vrin, 1988.

Jacoby, Liva \& Laura A. Siminoff. Empirical Methods for Bioethics: A Primer. Amsterdam: JAI Press, 2008.

Jonas, Hans. The Imperative of Responsibility. Hans Jonas \& David Herr (trans.). Chicago: The University of Chicago Press, 1984.

Kant, Immanuel. Groundwork for the Metaphysics of Morals. Allen Wood (trans.). New Heaven: Yale University Press, 2002.

Kuczewski, Mark G. \& Ronald Polansky (eds.). Bioethics: Ancient Themes in Contemporary Issues. Cambridge: The MIT Press, 2000.

Lobo, Alfonso Gomez \& John Keown. Bioethics and the Human Goods: An Introduction to Natural Law Bioethics. Washington, DC: Georgetown University Press, 2015.

Schulman, Adam et al. Human Dignity and Bioethics. Essays Commissioned by the president's council on Bioethics. Washington, DC: The President's Council on Bioethics, 2008.

Steinbock, Bonnie (ed.). The Oxford Handbook of Bioethics. Oxford: Oxford University Press, 2007.

Takala, Tuija et al. Cutting Through the Surface: Philosophical Approaches to Bioethics. Amsterdam: Editions Rodopi, 2009. 